\title{
LA CONSTITUCIONALIZACIÓN DE LA ESTABILIDAD PRESUPUESTARIA EN ESTADOS UNIDOS: LECCIONES DE UN DEBATE INACABADO*
}

\author{
The constitutionalization of a balanced budget rule \\ in the United States: lessons from an unfinished debate
}

\author{
Gabriel Moreno González \\ Investigador Derecho Constitucional \\ Universitat de València \\ Gabriel.Moreno-Gonzalez@uv.es
}

doi: http://dx.doi.org/10.18543/ed-65(2)-2017pp247-288

Recibido: 28.08.2017

Aceptado: 28.11.2017

\begin{abstract}
Resumen
El presente artículo tiene por objeto el estudio de la problemática jurídica que ha suscitado a lo largo de la reciente historia de los Estados Unidos la posible constitucionalización de la estabilidad presupuestaria, analizando las repercusiones de ésta a través de las experiencias estatales y del complejo marco institucional de la democracia norteamericana a nivel federal. Con ello, se perfilarán las cuestiones que más dudas suscitan en torno a la balanced budget desde el prisma constitucional y que pueden repetirse en cualquier proceso de similares características.
\end{abstract}

* Cómo citar / Citation 'Chicago-Deusto' (Autor-fecha / Author-date / Lista de referencias / Reference list entries): Moreno González, Gabriel. 2017. «La constitucionalización de la estabilidad presupuestaria en Estados Unidos: Lecciones de un debate inacabado». Estudios de Deusto 65, n. ${ }^{\circ}$ 2: 00-00. doi: http://dx.doi.org/10.18543/ed-65(2)-2017 pp247-288. 


\section{Palabras clave}

Economía constitucional; estabilidad presupuestaria; control jurisdiccional de constitucionalidad.

\section{Abstract}

This article aims to research on the legal matters that the possible constitutionalization of the balanced budget in the United States has raised in recent times, analyzing its impact from the perspective of the experience in some states and taking into account the great complexity that the institutional frame of the American democracy has at the federal level. By doing so, the main questions revolving around this issue from the constitutional point of view will be properly outlined, as these doubts may be repeated in similar processes.

\section{Keywords}

Constitutional economics; Balanced budget; Constitutional Review. 


\begin{abstract}
SUMARIO: I. INTRODUCCIÓN: LA ESTABILIDAD PRESUPUESTARIA EN EL TABLERO LIBERAL DE PODERES. II. LA BBR EN EL CONTEXTO DE LA ECONOMÍA CONSTITUCIONAL. III. LA REVOLT TAX: ¿HACIA UNA CONVENCIÓN CONSTITUCIONAL?. IV. LA PROBLEMÁTICA CONSTITUCIONAL DE LA ESTABILIDAD PRESUPUESTARIA. 1. La definición y el método contable. 2. Flexibilidad y transitoriedad. 3. Contenidos accesorios ... ¿necesarios?. 4. La evasión (¿legal?) de la estabilidad presupuestaria. V. EL PROBLEMA DE LA EJECUTORIEDAD: ¿JUECES HACIENDO CUENTAS?. VI. CONSIDERACIONES FINALES. BiBLIOGRAFÍA.
\end{abstract}

\title{
I. INTRODUCCIÓN: LA ESTABILIDAD PRESUPUESTARIA EN EL TABLERO LIBERAL DE PODERES
}

Si hay algo que caracterizó (y caracteriza) al liberalismo como movimiento político eso es, sin duda, la defensa de la limitación del poder del Estado en el marco de protección de los derechos individuales ${ }^{1}$. La preocupación liberal más auténtica se vio desde sus inicios canalizada en la Constitución en tanto mejor y más firme baluarte frente al temor a un retorno del ideario absolutista o de una expansión, sin límites, del nuevo Estado impersonal. Con la caída del Antiguo Régimen las cadenas que otrora restringían el ámbito de actuación del Monarca, ya fuera la religión, la tradición o los poderes intermedios, quedaron también completamente quebradas, mostrando con ello a los primeros liberales un campo baldío en el que tenían, a veces no sin dificultades, que reconstruir los límites al nuevo poder político que estaba naciendo ${ }^{2}$.

La experiencia estadounidense constituye, en este sentido, un caso paradigmático. Sin las ligaduras de la clase aristocrática y de la Monarquía que aún pervivirían durante décadas en la vieja Europa, los norteamericanos tuvieron que afrontar desde el inicio el reto de la construcción de una nueva República prácticamente ex nihilo. Y lo harían, tras su triunfo, a través de la articulación jurídica de los poderes políticos en la Constitución federal, la más antigua de las modernas que hoy persiste, mediante una hasta entonces

\footnotetext{
${ }^{1}$ Cfr. Norberto Bobbio, Liberalismo y democracia (México DF: Fondo de Cultura Económica, 2000).

${ }^{2}$ El vizconde de Tocqueville describiría el temor del primer liberalismo ante la nueva forma del Estado impersonal, libre de toda cadena heredada, con su magistral concisión: «Todos los poderes parecen acudir por sí solos hacia el centro, se acumulan en él con una rapidez sorprendente, y el Estado alcanza de golpe los límites extremos de su fuerza mientras que los particulares se dejan caer en un instante hasta el último grado de debilidad». Alexis de Tocqueville, La democracia en América (Madrid: Editorial Aguilar, 1989), vol. II, 349.
} 
novedosa ingeniería constitucional ${ }^{3}$. La limitación del poder a través de su separación, tanto horizontal (dos cámaras en el Congreso, mínimos poderes para el Presidente...), como vertical (federalismo), así como la restricción del margen de acción del mismo a través del reconocimiento y garantía de una serie de derechos fundamentales (Bill of Rights), vinieron acompañados de una preocupación constante en los jóvenes Estados Unidos por una posible extensión del Estado federal mediante el ejercicio, incontrolado, de sus facultades impositivas. La vinculación entre los deseos de limitar la discrecionalidad fiscal y el surgimiento mismo del moderno rule of law, presente en casi todos los procesos liberales, se predica especialmente de la Revolución norteamericana (No Tax Without Representation) y de la consiguiente defensa a ultranza de la propiedad privada como mejor cristalización de la esfera de libertad individual ${ }^{4}$. Las restricciones que se desplegaron frente a las posibles prácticas redistributivas de un poder político-fiscal fuerte, como el principio de generalidad tributaria, no fueron sin embargo tan contundentes como las que se dieron en el ámbito político; quizá debido en parte a la funcionalidad de éstas para con las primeras. La propia división del poder servía, en definitiva, para evitar la entonces tan temida «tiranía de las mayorías $\rangle^{5}$ también en el aspecto tributario.

Sin embargo, los recelos que el poder federal despertaba en el seno de los «republicanos», agrupados en torno a figuras tan prominentes como Jefferson y Madison, partidarios de mayor autonomía para los Estados, se vieron reflejados en los primeros años de la República americana en el ámbito fis$\mathrm{cal}^{6}$. Continuas tensiones alrededor de tal materia cruzaron este periodo, desde el rechazo a los planes de Hamilton de crear una deuda nacional, a la posibilidad misma de que la Federación aumentara sus competencias a través de una renovada capacidad fiscal. De ahí que los ojos de algunos republicanos viraran nuevamente hacia la Constitución, a la que consideraban en

${ }^{3}$ Roberto Blanco Valdés, El valor de la Constitución (Madrid: Alianza Editorial, 1998), 98 y ss.

${ }^{4}$ Algunos historiadores consideran, creemos que con cierta exageración, que una de las principales causas de las revoluciones inglesa, americana y francesa fue el alto nivel de deuda que mantenían sus Estados. Cfr.: Brinton Crane, The Anatomy of Revolution (Nueva York: Vintage Books, 1965), 28-39. Una visión sobre la revolución que sigue estando en vigor por su lucidez, y que destaca el papel de las instituciones anteriores a la Independencia que tenían las colonias y el rol que jugó el elemento fiscal, puede verse en Hannah Arendt, Sobre la Revolución (Madrid: Alianza Editorial, 2013). La importancia de la propiedad privada y sus categorías responde a lo que Fioravanti ha denominado como «modelo historicista», incrustado en el mundo anglosajón del primer liberalismo. Mauricio Fioravanti, Los derechos fundamentales (Madrid: Trotta, 2003), 31-35.

${ }_{5}^{5}$ El famoso $\mathrm{n}^{\mathrm{o}} 10$ de El Federalista, escrito por Madison, es relevante al respecto.

${ }^{6}$ Cfr.: Joseph Ellis, Founding Brothers (Nueva York: Vintage Books, 2000), 48-81. 
ocasiones demasiado federalista, para frenar tales tentaciones. Jefferson, el principal autor de la Declaración de Independencia, escribiría: «Desearía si fuera posible obtener una enmienda concreta para nuestra Constitución. Estaría dispuesto a depender de eso solo para la reducción de la administración de nuestro gobierno; quiero decir, un artículo adicional que regulara el poder de endeudamiento del Gobierno Federal $»^{7}$.

Fíjese el énfasis que dedica a la propuesta el mayor temeroso de entre los «Padres fundadores» del poder federal y del tamaño del Estado: «estaría dispuesto a depender de eso solo», de una enmienda constitucional que regulara, limitándolo, el endeudamiento de las instituciones de Washington. Aunque el mismo Jefferson no cumpliría con el ejemplo al comprar Luisiana mediante la emisión de deuda y su propia proposición nunca se materializaría en algo concreto, el miedo de sus «republicanos» a que los «federalistas» de Hamilton y Adams utilizaran mayores recursos económicos para ampliar los poderes centrales, fue evidente a lo largo de las primeras administraciones federales ${ }^{8}$.

En el seno de los Estados que formaban parte de la Unión el debate en torno a la necesidad de limitar la capacidad fiscal de sus respectivos Gobiernos sí pasó de las palabras a los hechos, hasta el punto de que hoy en día la práctica totalidad de los Estados tienen algún tipo de previsión constitucional sobre la estabilidad presupuestaria. Muchas de tales previsiones proceden, además, del contexto que proporcionó la primera crisis económica de entidad del nuevo país americano, que azotó las finanzas de medio mundo solo unos años después de la muerte del propio Jefferson. La crisis vino auspiciada por el espectacular crecimiento económico que las tres primeras décadas del siglo XIX dieron a los Estados Unidos, un país de dimensiones continentales que por entonces tenía una ilimitada capacidad de extensión territorial y de acumulación de riquezas. El aumento demográfico, gracias en buena medida a la llegada de inmigrantes, y las necesidades del comercio, provocaron una carestía de infraestructuras y medios de transporte que pronto la burguesía mercantil y financiera de la costa noreste supo demandar eficazmente. Los

${ }^{7}$ «I wish it were possible to obtain a single amendment to our Constitution. I would be willing to depend on that alone for the reduction of the administration of our government; I mean an additional article taking from the Federal Government the power of borrowing.» Thomas Jefferson, «Letter to John Taylor of Caroline», November 26, 1798, en The Writings of Thomas Jefferson (Washington DC: Memorial Edition), vol. 10. Traducción propia.

8 Jeffrey Needelman, «Deconstructing the Balanced Budget Amendtment: Fiscal Folly, Monetary Madness», UCLA Law Review, no 44 (1997): 1289 y ss. El autor recuerda la relevancia que tuvo el marco jurídico en la configuración de la estabilidad financiera y monetaria en el pensamiento de Hamilton, de ahí que sea el «Padre Fundador» más recordado por James Buchanan y la escuela de la Economía constitucional. 
Estados y las incipientes administraciones locales se embarcaron entonces en un sinnúmero de proyectos para crear tales infraestructuras, cuya financiación se logró gracias a la emisión de títulos de deuda valorados en millones de dólares ${ }^{9}$. El boom de títulos, vendidos por todo el mundo en el contexto de una incipiente globalización sin restricciones jurídicas, creó las condiciones propicias para que los movimientos especulativos se centraran en EEUU, y para que en 1837, bajo la presidencia del polémico Andrew Jackson, estallara una de las grandes crisis financieras de su historia ${ }^{10}$. Muchas de las administraciones, tanto estatales como municipales, tuvieron que declararse en bancarrota y reconocieron no poder afrontar sus altos niveles de deuda, en medio de la desconfianza de los inversores, la huida de capitales y el empeoramiento general de la economía norteamericana. Los sistemas fiscales de entonces, además, no estaban lo suficientemente perfeccionados como para ser máquinas efectivas de recaudación, y los proyectos que se financiaron con deuda habían sido planeados para costearse con los beneficios ulteriores de su propio uso.

La desconfianza de los inversores hacia el nuevo país fue tal durante los siguientes años que los Estados, en un intento por recuperar su simpatía, y recordando las palabras de Jefferson, impulsaron la constitucionalización de límites al endeudamiento y de previsiones específicas tendentes a hacer los pagos de las deudas contraídas jurídicamente vinculantes (full faith and credit). La estabilidad presupuestaria se fue así convirtiendo en el siglo XIX en una constante en las Constituciones estatales norteamericanas, y aunque fuera desplegada con grandes diferencias entre los diferentes Estados, todas abordaron alguna de las siguientes previsiones: la estabilidad presupuestaria o garantía de déficit cero; el requerimiento de que la emisión de nuevos bonos sea aprobada por referéndum; que éstos sean aprobados por mayorías cualificadas (generalmente $3 / 5$ ); o limitaciones sobre deuda garantizada ${ }^{11}$.

${ }^{9}$ Sobre este contexto, y sobre la importancia que como referente tuvo además el éxito de la construcción del Canal del Eire en Nueva York, puede verse Lance Davis y Robert Cull, «International Capital Movements and American Economic Growth 1820-1914», en Stanley Engerman y Robert Gallman., eds., The Cambridge Economic History of the United States (Nueva York: Cambridge University Press, 1993).

${ }_{10}$ Roderick Kiewiet y Kristin Szakaly, «Constitutional Limitations on Borrowing: An Analysus if State Bonded Indebtedness»), California Institute of Technology (1996): 65. Como indican los autores, los títulos se vendieron sobre todo a inversores holandeses y británicos.

${ }^{11}$ La deuda garantizada es aquella que se emite con el compromiso por parte del Estado de adscribir a su pago determinados impuestos, y en caso de que éstos sean insuficientes, tener que crear nuevos a tal fin. En general, sobre este proceso, puede verse nuevamente Kiewiet y Szakaly, ibid.: 65 y ss. Un análisis de estas disposiciones estatales, en 
Sin embargo, este proceso de constitucionalización de la estabilidad presupuestaria no se intentó en el ámbito federal, precisamente aquel que depositaba los temores originarios de los «republicanos». La explicación es más simple de lo que cabría esperar: el limitado tamaño de la administración federal y sus reducidas funciones, en un siglo XIX donde imperaba el Estado mínimo y apenas existían prestaciones positivas por parte de éste, hacían del superávit o, cuanto menos, de los presupuestos equilibrados, algo tan normal que hoy nos extrañaríamos en grado sumo ${ }^{12}$. Solo durante las guerras el déficit se desbocaba y la deuda subía, pero en seguida la recuperación de la coyuntura permitía financiar los compromisos adquiridos gracias al crecimiento, prácticamente continuo, de una economía estadounidense que a principios del siglo XX ya se homologaba, en ciertos aspectos, a las grandes potencias europeas ${ }^{13}$. Como reconoce Buchanan: «el primer siglo y medio de nuestra historia política nacional encarnó la norma de la estabilidad presupuestaria (balanced budget). Esta regla no estaba escrita en el texto constitucional como tal, pero era parte de un aceptado consenso de actitudes acerca de cómo el gobierno debería y debe afrontar sus asuntos fiscales» ${ }^{14}$.

Por el contrario, el New Deal acabaría con esta tendencia, y mediante una intervención activa del Estado en la economía y el establecimiento de los primeros pilares del sui generis Estado Social norteamericano, la deuda

Yilin Hou y Daniel Smith, «Framework for Understanding State Balanced Budget Requirement Systems: Reexamining Distintive Features and an Operational Definition», Public Budgeting and Finance Review, 26, n 3, (2006): 32-43.

${ }_{12}$ Curiosamente, como indica Seto, la mayor parte de los ingresos federales provenían de los aranceles que protegían el mercado interno y los intereses de la burguesía y los pequeños comerciantes, por lo que la opinión de la mayoría de la sociedad sobre los presupuestos federales solía ser positiva y permitía una mejor recepción de los intentos, no en balde, de muchos presidentes por aumentar la presencia de Washington en el país. Theodore Seto, «Drafting a Federal Balanced Budget Amendment That Does What It Is Supposed To Do (And No more)», The Yale Law Journal, 106, nº 5, (1997): 1467.

13 Anita Krishnakumar, «In defense of the debt limit statute», Harvard Journal on Legislation, 42, $\mathrm{n}^{\circ} 71$ (2005): 140-145. Las guerras que provocaron ciertas subidas en el nivel de deuda federal fueron, por este orden, la Anglo-Estadounidense de 1812, la invasión de México en 1847, la Guerra de Secesión en los 60 (donde por primera vez se emitieron bonos de guerra), y ya en el siglo XX, la Primera Guerra Mundial a partir de la entrada del país norteamericano en el tablero europeo (1917).

14 «The first century and one-half of our national political history did, indeed, embody a norm of Budget balance. This rule was not written into the constitutional document, as such, but rather it was a part of an accepted set of attitudes about how government should, and must, carry on its fiscal affairs». James Buchanan, "Clarifying confusion about the Balanced Budget Amendment», National Tax Journal, XLVIII, nº 3 (1995): 347. Traducción propia. 
empezaría a naturalizarse como un instrumento más del Gobierno Federal ${ }^{15}$. El ideario keynesiano, asentado tras la Segunda Guerra Mundial y con cierta hegemonía entre la élite dirigente y académica occidental, consolidaría la tendencia al endeudamiento masivo y a presentar, desde entonces, déficit desequilibrados ${ }^{16}$. Siguiendo a Saturno y Lynch: «esta idea fue básica en la premisa de que los gobiernos debían equilibrar la economía, no simplemente el presupuesto» ${ }^{17}$. De ahí que el fantasma de Jefferson apareciera y su proposición, entonces olvidada, se recuperara para intentar llevarse, directamente, a la Constitución Federal. Aunque los primeros intentos al respecto fueron, en verdad, excesivamente tímidos.

Así, en 1935, durante la presidencia de Roosevelt, el senador Millard Tydings propuso un límite a la capacidad de endeudamiento del Estado, pero sin referirse explícitamente a una reforma constitucional; y al año siguiente, ahora sí, el representante de Minnesota Harold Knutson planteó por primera vez una enmienda a la Constitución de los Estados Unidos para juridificar la balanced budget indexando los presupuestos a la evolución del PIB per cápita. Dos años después, a pesar del rechazo de ambas iniciativas, la American Taxpayers Association presentó un proyecto de enmienda similar al de Knutson, que aunque provocó cierto debate (a pesar de que seguía siendo bastante débil), volvió a ser rechazada por no contar siquiera con los apoyos suficientes como para poder ser tramitada ${ }^{18}$. Sin embargo, la asociación no se dio por vencida y miró, por primera vez, al olvidado mecanismo que el artículo V de la Constitución, sobre la reforma de la misma, recoge: la posibilidad de convocar una Convención Constitucional cuando así lo requieran 2/3 de los Estados federados. Los intentos de que éstos enviaran requerimientos

${ }^{15}$ En verdad, como indica de nuevo Krishnakumar, hubo una cierta tendencia desde la I Guerra Mundial, con la aprobación de las Liberty Bonds Acts, a ceder cada vez más poder presupuestario al Gobierno Federal desde el Congreso. Éste, desde 1917, dejó de ser el único protagonista en la emisión de deuda pública. Anita Krishnakumar, «In defense of the debt limit statute», 145-160.

${ }^{16}$ Una crítica desde la Economía constitucional a Keynes y el impacto de sus políticas, según los autores, en el sistema político, puede verse en James Buchanan y Richard Wagner, Democracy in Deficit: The Political Legacy of Lord Keynes, (New York: Academic Press, 1977).

17 «This idea was based on the premise that governments should balance the economy, not simply de budget», citado en James Saturno y Megane Lynch, «A Balanced Budget Constitutional Amendment: Background and Congressional Options», Congressional Research Service, $\mathrm{n}^{\circ} 20$ (2011): p. 2 y ss. Traducción propia.

18 Sobre la historia de las enmiendas constitucionales en EEUU, es imprescindible la obra de Richard Berstein y Jerome Agel, Amending America, (Kansas: University Press of Kansas, 1995). Sobre estas propuestas en particular, con un sucinto análisis de las que posteriormente se presentarían hasta los 80, puede verse James Savage, Balanced Budgets and American Politics, (New York: Cornell University Press, 1988). 
en tal sentido fueron, de nuevo, infructuosos ${ }^{19}$, al igual que los posteriores que se presentarían ${ }^{20}$. Estados Unidos pudo entrar así en lo que se conocería como la Golden Age del capitalismo, sin restricciones constitucionales sobre sus presupuestos y con un crecimiento económico que parecía imparable y frenaba todo intento de limitación constitucional de la expansión fiscal. Hasta la década de los 70.

A pesar de estos intentos fracasados, y de la constitucionalización exitosa anterior en los Estados de la estabilidad presupuestaria, ello no ha de llevarnos a pensar que ésta era interpretada en los términos y categorías actuales. Hasta mediados de los 70, la balanced budget se medía en Estados Unidos bajo criterios más políticos que económicos, en la creencia de que una regla de equilibrio presupuestario a nivel federal constreñiría la posible expansión, no deseada por sus impulsores, de la administración central. Era siempre el mismo tablero en que se movían los «republicanos» y los «federalistas», el de la articulación liberal de los frenos y contrapesos, de la división y limitación efectiva del poder político. No abogaban por la constitucionalización de la estabilidad presupuestaria porque creyeran que ésta garantizara mejor el orden de mercado ni, por supuesto, aplicaban las modernas teorías del Leviatán administrativo asociado a la crítica al Estado Social. Aunque tales concepciones no tardarían de aparecer en un marco de renovado interés constitucional por la Balanced Budget Rule (BBR, en adelante).

\section{LA BBR EN EL CONTEXTO DE LA ECONOMÍA CONSTITUCIONAL}

Como decimos, no será hasta la segunda mitad de los años 70 cuando el debate en torno a la constitucionalización de la estabilidad presupuestaria a nivel federal se revitalice y lo haga, además, bajo fundamentos teóricos diferentes. En efecto, y aunque ya se pueden ver algunas trazas importantes de su teoría en la escuela ordoliberal alemana, la «Economía constitucional» (EC, en adelante) elaborará durante esa década un sólido cuerpo doctrinal que defenderá, explícitamente y con argumentos de economía política, la necesidad de que las Constituciones incorporen férreas restricciones al margen de acción fiscal de los Estados. James M. Buchanan será, en este sentido, la figura más

19 David Kyvig, «Refining or Resisting Modern Government? The Balanced Budget Amendment to the U. S. Constitution», Akron Law Review, 28, n 2, (1995): 103.

${ }^{20}$ Desde el intento de la Asociación, numerosas medidas de este tipo se presentaron por parte de Representantes o Senadores a lo largo de las tres décadas siguientes, pero ninguna tuvo la oportunidad, siquiera, de ser tramitada. 
importante de la nueva escuela (también llamada de Virginia), y sus aportes, los más relevantes a la misma ${ }^{21}$.

Si bien la traslación del análisis económico al jurídico no es propia únicamente de la Economía constitucional buchaniana (Posner, Becker... incluso Milton Friedman), será ésta la que juegue a nivel teórico un papel preponderante en cuanto a la constitucionalización de la BBR en Estados Unidos; algo que hará desde el edificio de sus postulados, enraizados en una concepción filosófica subyacente de, en ocasiones, compleja elaboración. A fuerza de síntesis, éstos descansarían en una defensa radical del individualismo metodológico que les llevará a defender, a su vez, la unanimidad como parámetro óptimo en la toma de decisiones democrática. Bajo este patrón, la posibilidad de veto de un solo individuo asegura que las propiedades e intereses de éste, en sentido genérico, queden siempre salvaguardadas frente a la «tiranía de las mayorías» de las que nos hablaba Madison $^{22}$. La unanimidad, sin embargo, conlleva unos costos considerables en el marco de las democracias constitucionales contemporáneas, por lo que Buchanan permite que tal exigencia se rebaje dependiendo de la importancia de las normas afectadas. Al considerar las fiscales como potencialmente peligrosas por cuanto pueden subvertir el statu quo a través de lo que Buchanan denomina directamente como técnicas de «rapiña», y que no son más que los mecanismos redistributivos, la Economía constitucional las sitúa en el centro de sus análisis y preocupaciones. Si la unanimidad no puede alcanzarse, o de hacerlo es con un coste político intolerable (retrasos prolongados en la decisión, v.g.), lo óptimo será siempre lo que más se acerque a ese parámetro. Cuanto mayor sea el número de individuos que se necesitan para tomar una decisión, más protegida estará la propiedad y la libertad frente a los deseos siempre cambiantes de las mayorías. La temida redistribución, contraria a la libertad individual en la medida en que conlleva para un grupo determinado la sustracción de recursos que, según Buchanan, justamente le pertenecen, puede alejarse a través del establecimiento de la necesidad de mayorías cualificadas, lo más cercanas posibles

${ }^{21}$ No en vano, Buchanan recibiría el Premio Nobel de Economía en 1986. En general, para un análisis de la Economía constitucional, Cfr.: Pedro Puy Fraga, Economía política del Estado constitucional: fundamentos de la Economía constitucional, (Barcelona: Cedecs Editorial, 1996).

22 Para comprender la concepción holística del autor es esencial James Buchanan, Los límites de la libertad: entre la anarquía y el Leviatán, (Buenos Aires: Katz Editores, 2009). Buchanan escribió esta obra en 1975 en el contexto de la discusión abierta por la publicación, unos años antes, de la Teoría de la Justicia de Rawls y la revitalización que entonces se vivió de los paradigmas contractualistas. Cfr. Fernando Vallespín, Nuevas teorías del contrato social: John Rawls, Robert Nozick y James Buchanan, (Madrid: Alianza Editorial, 1985). 
a la unanimidad, para la toma de decisiones en materia fiscal. Y el instrumento más adecuado para recoger tales previsiones, por su propia naturaleza indisponible para las mayorías ordinarias (contramayoritaria) y su fuerza supralegal, es la Constitución y la virtualidad jurídica subsiguiente que desprende ${ }^{23}$. Además, la Norma Fundamental es para Buchanan el paradigma del precompromiso (en el sentido de Elster ${ }^{24}$, en tanto constituye la traslación más exacta del pacto societatis en el que, unánimemente, la sociedad se ha otorgado a sí misma las reglas de convivencia. En esa unanimidad, dice Buchanan, también entran los privilegiados económicamente, que han tenido que transigir con algunas demandas de las mayorías sociales para poder consolidar el nuevo statu quo. El velo de la ignorancia rawlsiano, a su vez, da cobertura a los débiles mecanismos redistributivos que puedan haberse cedido en el momento constituyente y cuya importancia nunca se niega desde la EC. Ahora bien, dichos mecanismos redistributivos han de estar sujetos en todo momento a la Constitución como dique jurídico frente a los deseos de las mayorías si se quiere mantener el pacto fundante de la unanimidad y la inclusión subsiguiente en él de las clases privilegiadas. De ahí que desde tal precompromiso se proyecten, dice Buchanan, una serie de instrumentos jurídicos tendentes a frenar la posible expansión del Estado y su intervención en la economía, que siempre tienden a ir destinados a garantizar mayores cotas de redistribución para las mayorías a costa de la libertad y la propiedad individuales de las minorías (privilegiadas) $^{25}$. Los frenos jurídico-constitucionales a tal expansión se yerguen en la Economía constitucional, por tanto, como los mejores baluartes en defensa del individuo y su propiedad (en sentido smithiano). La posibilidad de que el Estado se extralimite e intente subvertir redistributivamente el statu quo tiene, además, un actor clave: la Administración pública.

La Economía constitucional no estaba sola en los años 70 en el análisis economicista y desde la economía política de la importancia de la

${ }^{23}$ Pedro Puy Fraga, Economía política del Estado constitucional: fundamentos de la Economía constitucional, 218-267.

24 John Elster, Ulises y las sirenas: estudios sobre la racionalidad e irracionalidad, (Madrid: Fondo de Cultura Económica de España, 2002).

${ }^{25}$ La concepción del individuo como un agente racional, calculador y maximizador permanente de sus perspectivas de ganancias (homo economicus), puede encontrarse más extensamente en James Buchanan y Gordon Tullock, El cálculo del consenso, (Madrid: Editorial Aranzadi, 2015). Ésta es, además, una de las obras más famosas y populares de la Economía constitucional, donde se intenta argumentar la necesidad de la unanimidad en la toma de decisiones o, cuanto menos, de las situaciones más cercanas a la unanimidad. El consenso se predica, en este sentido, del momento constituyente en el que se fundamenta la Constitución. 
Administración pública. Durante toda la década se publicaron constantemente estudios sobre la naturaleza de la misma y en la incidencia de su despliegue en los factores económicos. Buchanan proyectará, en este sentido, el conjunto de los planteamientos de su escuela en la Administración, la cual revestirá siempre, según él, una tendencia inmanente a la expansión. Como quiera que está compuesta por individuos, y que los individuos en la EC son siempre homo econonicus que buscan el mayor beneficio posible en todas sus acciones, tales gestores públicos tenderán permanentemente a aumentar su prestigio y capacidad de influencia a través de la ampliación de las funciones y competencias administrativas. Si a ello le sumamos que éstas son el vehículo concreto de las aspiraciones redistributivas de las mayorías (mediante prestaciones sociales, vg.), la defensa del statu quo desde el texto constitucional ha de tener como objetivo prioritario la limitación de la capacidad expansiva de la Administración, el verdadero brazo ejecutor del Estado. Y ello, se dice desde la EC, puede conseguirse a través de la constitucionalización misma de las políticas fiscales que permitiría la proyección, desde la unanimidad fundante del pacto, de los límites y restricciones más adecuados a tal fin. Atar desde la Constitución al Leviatán que siempre amaga con levantarse para proteger el valor de la libertad individual. Y los mecanismos jurídicos más adecuados para ello los encontrarán en la constitucionalización de la estabilidad presupuestaria y financiera, en la incorporación de una BBR a la Constitución y en la exigencia desde la misma de que se necesiten mayorías cualificadas (las más cercanas a la unanimidad) para poder incrementar los impuestos y evitar, con ello, la tan temida extralimitación estatal-administrativa ${ }^{26}$.

Esta concepción renovada del planteamiento liberal en torno a la estabilidad presupuestaria será la que se mezcle en los años 70 con las connotaciones más clásicas (antifederalistas) de la misma, que como hemos visto ya tenían un recorrido importante en la historia de los Estados Unidos, para impulsar así los primeros intentos con serias posibilidades de éxito de llevar la BBR a la Constitución Federal. El matiz contramayoritario que incorpora este giro conceptual podrá, a fortiori, comprobarse continuamente en el nuevo tablero que se despliega.

\section{LA REVOLT TAX: ¿HACIA UNA CONVENCIÓN CONSTITUCIONAL?}

La desafección política de mediados de los 70 era palpable en los Estados Unidos. El desastre de la Guerra de Vietnam había creado un fuerte rechazo

${ }^{26}$ James Buchanan y Geoffrey Brennan, El poder fiscal: fundamentos analíticos de una constitución fiscal, (Madrid: Unión Editorial, 1987). 
en amplios sectores de la sociedad hacia la clase política, y la Crisis del Petróleo vino a frenar el crecimiento económico continuo, estanflación mediante, que se había experimentado desde la Segunda Guerra Mundial. Escándalos como el del Watergate y la consiguiente dimisión del Presidente, no ayudaron precisamente a atenuar este recelo hacia las instituciones de Washington, que tuvieron, además, que incrementar la presión impositiva y aumentar los niveles de deuda para hacer frente a las consecuencias de la cri$\operatorname{sis}^{27}$. La cosmovisión keynesiana se puso en entredicho desde la Academia, los think tanks ${ }^{28}$ y la propia clase política ${ }^{29}$.

En este contexto es en el que se encuadra la llamada Revolt Tax, o «revuelta del contribuyente ${ }^{30}$, donde el ideario de la Economía constitucional pareció tomar forma y aterrizar en la arena política. Uno de los principales escenarios de tal «revuelta» fue California, donde en 1978 se llegaría a aprobar la denominada «Proposición 13», algo que entusiasmaría sobremanera a Buchanan y a los miembros de la $\mathrm{EC}^{31}$. En ese año, el cuerpo electoral del Estado aprobó mediante referéndum la limitación constitucional de subidas de impuestos, que a partir de entonces no podrían sobrepasar un tanto por ciento del valor del hecho imponible, incorporando además en la norma constitucional la necesidad de que fueran mayorías cualificadas las que aprobaran cualquier modificación impositiva ${ }^{32}$. Para Buchanan, que apoyó activamente la Proposición, ésta venía a constituir una victoria sobre las

${ }^{27}$ Un resumen de todas estas circunstancias, y del aumento en los niveles de deuda, puede verse en Iwan Morgan, «Unconventional Politics: The Campaign for a Balanced Budget Amendment. Constitutional Convention in the 1970s», Journal of American Studies, Cambridge University Press, $\mathrm{n}^{\mathrm{o}} 32$, (1988): 422 y ss.

${ }_{28}$ El abandono del fordismo y las transformaciones en el corazón del Estado Social vinieron acompañadas de la eclosión de nuevas teorías explicativas de la realidad de la mano de pensadores y economistas como Hayek (Premio Nobel en 1976), Milton Friedman (Premio Nobel en 1976), o el mismo Buchanan (Premio Nobel en 1986).

${ }_{29}$ El senador de Maryland James Clark, uno de los grandes impulsores de la BBR en la Constitución durante los 70, decía: «Las universidades que han enseñado las teorías de Lord Keynes y los políticos que las han distorsionado para sus propias necesidades, son los arquitectos de nuestro presente dilema y deben cargar con la responsabilidad». Citado en Iwan Morgan, ibid.: 423. Traducción propia.

30 Sobre la «revolt taxt» y sus antecedentes, anclados en el clima de desconfianza hacia las instituciones de Washington que fue impulsado, entre otros factores, por el desastre de Vietnam, puede verse el completo estudio de Robert Kuttner, Revolt of the Haves: Tax Rebellions and Hard Times, (Nueva York: Simon and Schster, 1980).

31 James Buchanan y Geoffrey Brennan, El poder fiscal: fundamentos analíticos de una constitución fiscal, 51 y ss.

32 Sobre la revuelta en el contexto californiano, vide Bruce Cain y Roger Noll, «Institutional causes of California's Budget Problem», Stanford Institute for Economic Policy Research, $\mathrm{n}^{\mathrm{o}} 10,(2010)$. 
posibilidades posteriores de «rapiña» redistributiva por las cambiantes mayorías sociales ${ }^{33}$.

El éxito de la Proposición en California, el Estado más rico de cuantos integran la Unión, constituyó un punto de inflexión en el movimiento que había comenzado unos años antes, en $1975^{34}$. El objetivo: constitucionalizar la estabilidad presupuestaria a nivel federal a través de la convocatoria de una convención constitucional. Rescatar así el intento de la American Taxpayers Associaton durante el New Deal, pero esta vez haciéndolo desde una estrategia integral y en medio de un contexto económico y político propicio al mismo. En efecto, el artículo V de la Constitución de los Estados Unidos establece dos medios para reformar su propio texto: o a través de la aprobación de una enmienda por $2 / 3$ de cada cámara del Congreso (la de Representantes y el Senado), o mediante el requerimiento de convocatoria de convención constitucional por $2 / 3$ de los Estados (34); siendo en ambos casos la posterior ratificación de $3 / 4$ de estos últimos. Hasta ese momento, y hasta ahora, todas las enmiendas de la vetusta Constitución federal (27) han seguido el primer procedimiento, es decir, han sido aprobadas por ambas cámaras sin necesidad de convocar una asamblea constitucional, que no ha vuelto a repetirse desde la Convención originaria ${ }^{35}$. Ello es debido, en gran medida, a la dificultad de que tal cantidad de Estados, con intereses tan divergentes entre sí, cuando no directamente opuestos, converjan en la defensa de una determinada modificación ${ }^{36}$, aparte de la complejidad misma que reviste el procedimiento y la incertidumbre que, como veremos, arroja.

A pesar de estos inconvenientes, el movimiento nacido en torno a la necesidad de llevar la estabilidad presupuestaria a nivel federal se centró, como decíamos, en la activación, sin precedentes, de este mecanismo. Al nutrirse especialmente de los recelos anti-establishment y anti-federales que estaban en la base de la Revolt Tax y del clima de desafección de la época, no era posible a corto plazo que se alcanzase una mayoría suficiente en las dos cámaras de Washington para aprobar una enmienda constitucional, y más con la llegada al poder de Jimmy Carter (1977-1981). Los Estados ofrecían, pues, la

33 James Buchanan, Los limites de la libertad: entre la Anarquía y el Leviatán, 134 y SS.

34 Sobre la influencia de la Proposición 13 de California, Arthur O'Sullivan, Terri Sexton y Steven Sheffrin, «Proposition 13: Unintended Effects and Feasible Reforms», National Tax Journal, no 55, (1999).

${ }^{35} \mathrm{Y}$ aun habría que analizar ésta, ya que como tal se convocó para reformar los artículos de la Confederación, no para aprobar ex nihilo una Constitución Federal.

${ }^{36}$ Las diferencias entre la región de Nueva Inglaterra y el Medio Oeste, entre el noreste y el sur, o entre California y Ohio, por ejemplo, no sólo se limitan a preferencias políticas, sino a diferentes intereses socioeconómicos en muchos casos altamente acusados. 
única posibilidad ${ }^{37}$, pudiéndose aprovechar además los propios recelos que desde éstos se mantenían frente los poderes centrales. Así, la National Taxpayers Union (NTU, en adelante), fundada en 1969 pero poco conocida hasta entonces, fue impulsada por los partidarios de la estabilidad presupuestaria, especialmente a partir de 1975, y desde ella se impulsó y articuló la campaña para recabar los 34 requerimientos necesarios en aras de convocar la primera convención constitucional de la historia norteamericana ${ }^{38}$.

Frente al «establishment despilfarrador», la NTU, junto a políticos de ambos partidos, aunque con una predominancia clara de republicanos ${ }^{39}$, consiguió que en muy poco tiempo los Estados comenzaran a emitir los requerimientos necesarios para activar el artículo V. Las primeras asambleas legislativas en hacerlo fueron las de Maryland y Missisippi en el mismo año de 1975, y en los siguientes años, ya bajo la presidencia de Carter, el número no cesó de incrementar a pesar de la, en ocasiones, falta de transparencia de los procesos estatales, algunos de los cuales ni siquiera mantuvieron hearings para estudiar la oportunidad o no del requerimiento ${ }^{40}$. Sin embargo, en cuanto el número de éstos fue acercándose al exigido, 34, tanto el propio Gobierno de Carter como el establishment de ambos partidos comenzaron una dura contra-campaña, lanzando otro movimiento, Citizens for the Constitution $^{41}$ y presentando los puntos débiles de los partidarios de la NTU. No

37 Aunque el senador Birch Bayh intentó en un inicio que el Congreso tramitara, al menos, una proposición de enmienda constitucional, pronto se dieron cuenta de lo infructuosas que serían todas las acciones en ese sentido.

${ }^{38}$ La dirección de la NTU estaba integrada por algunos miembros que incluso mostraban influencias libertarias y anarcocapitalistas. David Kyvig, «Refining or Resisting Modern Government? The Balanced Budget Amendment to the US Constitution», Akron Law Review, $\mathrm{n}^{\mathrm{o}}$ 28, (1995): 104. Sobre el movimiento y sus iniciativas, vide. Russel Caplan, Constitutional Brinkmanship: Amending the Constitution by National Convention, (New York: Oxford University Press, 1998): 78 y ss.; e Iwan Morgan, «Unconventional Politics: The Campaign for a Balanced Budget Amendment. Constitutional Convention in the 1970s», 424.

39 Bruce Ackerman, We the People: Foundations, (Cambridge: Cambridge University Press, 1991): 86-112. El conocido autor calificaría a este movimiento como conservador y propio de la «nueva derecha» norteamericana.

${ }^{40}$ Iwan Morgan, ibid.: 427. Figura clave de este éxito del movimiento de la NTU fue el famoso gobernador demócrata de California, Jerry Brown, que aunque en un inicio era reacio a la BBR, no tardó en aprovechar el éxito de la Proposición 13 en su propio Estado para sumarse a la campaña a nivel nacional, con un lenguaje anti-establishment que, a pesar de ser parecido al de los republicanos, hacía más hincapié en elementos de justicia social.

${ }^{41}$ Liderada por Thomas P. O'Neill, vicegobernador de Massachusetts, y miembro destacado de una de las grandes sagas políticas estadounidenses, hijo del entonces Speaker de la Cámara de Representantes, «Tip» O'Neill. Iwan Morgan, ibid.: 439. Otras 
obstante, en vez de centrarse en los argumentos económicos que podrían desprenderse para rechazar la constitucionalización de una BBR a nivel federal, lo hicieron sobre argumentos eminentemente jurídicos y en el temor a que se abriera, por primera vez desde Filadelfia, la primera convención constitucional. El propio nombre del contra-movimiento lo refleja: de un debate económico se pasó a uno político y jurídico en defensa de la Constitución y sus valores. Y es que los temores estaban, en gran medida, justificados. Las dudas que se comenzaron a plantear, y que aún hoy no se han resuelto, sobre el alcance, los límites e incluso los procedimientos de una convención constitucional, creaban un mar de incertidumbre que ni los más doctos juristas norteamericanos sabían (ni saben) despejar ${ }^{42}$.

La parquedad del artículo $\mathrm{V}$ y sus previsiones, la falta de precedentes y la naturaleza política misma de una convención constitucional, también preocupaba a sus propios impulsores. Según el movimiento de la NTU, la futura convención que se convocase en cuanto se consiguiera el número de requerimientos necesario, estaría limitada única y exclusivamente a la constitucionalización de la estabilidad presupuestaria. Pero... ¿podrían limitarse jurídicamente, a priori, las decisiones de una convención constitucional depositaria de la soberanía nacional? Y es más, ¿podría ello hacerse a pesar del silencio que en este sentido desprendía el propio artículo V? Algunos constitucionalistas respondieron (y siguen respondiendo hoy) negativamente, al sostener que la activación del poder constituyente conlleva siempre, por su propia naturaleza, la ausencia de restricciones jurídicas, que no pueden en ningún caso coartar o limitar la verdadera traslación de la voluntad soberana del pueblo estadounidense ${ }^{43}$. Pero incluso si se admitiera la tesis de la NTU de una convención constitucional limitada previamente... ¿qué o quién establecería el límite y su alcance? Los requerimientos que se enviaron

organizaciones de similar naturaleza fueron «The Committee to Preserve the Constitution» o «People for the Constitution», cuyos nombres son también significativos de la naturaleza del debate que se mantuvo.

${ }^{42}$ La Casa Blanca solicitó un informe al destacado constitucionalista Laurence Tribe sobre el particular, informe que recalcó la incertidumbre jurídica que presidiría una futurible convención constitucional. David Kyvig, «Refining or Resisting Modern Government? The Balanced Budget Amendment to the US Constitution», 109.

${ }^{43}$ Sobre el aparente «vacío constitucional» del escueto artículo V de la Constitución de los Estados Unidos, en este contexto, puede verse Laurence Tribe, «Issues Raised by Requesting Congress to Call a Constittutional Convention to Propose a Balanced Budget Amendment», Pacific Law Journal, 10, (1979), y Walter Dellinger, «The Recurring Question of the 'Limited' Constitutional Convention», Yale Law Journal, 88, no 8, (1979). En general, sobre las posibilidades que brinda el art. V, sus limitaciones y alcance, Cfr.: Michael Stokes Paulsen, «A General Theory of Article V: The Constitutional Lessons of the Twenty-seventh Amendment», Yale Law Journal, 103, nº 8, (1993). 
al Congreso para convocarla eran, de hecho, bastante diferentes entre sí, y su falta de similitud impediría, en consecuencia, cualquier limitación taxativa ${ }^{44}$.

La caja de Pandora de la Constitución, un documento que había demostrado su solidez y estabilidad a lo largo de doscientos años, podía abrirse y cambiar radicalmente el sistema político norteamericano por primera vez desde el nacimiento de la República. Desde la oposición a la convención y a la BBR éste constituyó, de hecho, el principal argumento que se blandió para frenar la inminente activación del poder constituyente. Los temores que ello despertara, junto a amenazas veladas de recortes presupuestarios en las transferencias federales a los Estados como consecuencia de la entrada en vigor de la BBR, así como las luchas intestinas en el interior de ambos partidos, hicieron que finalmente la iniciativa fracasara y que el número de requerimientos estatales fuera siempre insuficiente ${ }^{45}$.

Este fracaso, sin embargo, no frenó el empeño de los partidarios de la BBR, que con la llegada a la Presidencia de Ronald Reagan (1981-1989), vieron incrementadas sus esperanzas. Durante su mandato el equilibrio presupuestario se volvió un tema recurrente, pero los excesivos gastos militares en el contexto de la Guerra Fría y los recortes impositivos sobre las grandes fortunas, provocaron los efectos contrarios y permitieron que el déficit y la deuda pública se desbocaran. Esta contradicción, entre lo que Reagan defendía en público y su ideología, y la realidad fiscal de su mandato, hizo que de nuevo el movimiento cobrara relativa fuerza. Pero en este caso la respuesta de parte del establishment fue diferente: en vez de alertar sobre la posibilidad de una convención constitucional, directamente intentaron alejarla anticipándose y modificando desde el Congreso la Constitución para incorporar la $\mathrm{BBR}^{46}$. Así, un ala del Partido Republicano, liderada por el senador Hatch, propuso en 1981 una enmienda constitucional donde además de incorporar la estabilidad presupuestaria se establecía la necesidad de que cualquier incremento fiscal en el nivel federal fuera aprobado por mayorías cualificadas (de nuevo, Buchanan resuena aquí). La proposición, conocida entonces como

${ }^{44}$ El caso Coleman v. Miller ya había establecido en 1939, aunque con matices, que la interpretación de los requerimientos estatales era una cuestión política de la que la Corte Suprema se evadía. Vid. David Kyvig, ibid.: 109.

45 Iwan Morgan, «Unconventional Politics: The Campaign for a Balanced Budget Amendment. Constitutional Convention in the 1970s», 439-442.

46 Algo parecido se intentó, aunque esta vez con éxito, a principios del siglo XX. Ante la posibilidad, aunque remota, de la convocatoria de una convención constitucional por ir reuniendo rápidamente el número de requerimientos necesarios, el Congreso se adelantó a lo que querían los convocantes, la elección directa de los Senadores, enmendando él mismo la Constitución en 1912 (Enmienda XVII). Este paralelismo lo traza también James Bowen, «Enforcing the Balanced Budget Rule», Seton Hall Constitution, n 4, (1993): 569. 
«enmienda consenso», fue debatida a lo largo de la presidencia de Reagan, el cual mostró incluso sus simpatías por la misma ${ }^{47}$, y llegó a ser aprobada por una holgada mayoría en el trámite del Senado, pero la fuerte hegemonía demócrata en la Cámara de Representantes la acabó descartando finalmente. A ello se sumó la aprobación en 1985 de la ley conocida como Gramm-Rudman-Hollings Act, cuyo objeto era combatir en sede legal el déficit público a largo plazo, y que terminó de atenuar a los partidarios más fervientes de la constitucionalización ${ }^{48}$.

Aunque los intentos de enmienda constitucional se sucedieron en los años posteriores, no sería hasta 1995, durante la presidencia de Bill Clinton, cuando de nuevo la posibilidad de constitucionalizar la estabilidad presupuestaria tuvo cierta posibilidad de éxito. El avance republicano en las elecciones legislativas y el programa que a ellas llevaron, donde figuraba en un lugar preeminente la BBR, permitieron que un nuevo proyecto de enmienda constitucional se presentara y debatiera ${ }^{49}$. De este modo, la Cámara de Representantes llegó a aprobarlo, pero esta vez fue el Senado en el que, en uno de los célebres ejemplos que nos permiten los checks and balances norteamericanos, frenó la proposición; aunque, eso sí, por muy poco margen. Finalmente, la enmienda de 1995 se intentaría aprobar dos años después, con un texto muy similar, pero nuevamente sería aplacada en el Senado ${ }^{50}$. La última vez en que tal pretensión llegó al Congreso con posibilidades de éxito fue en noviembre de 2011, pero la Cámara de Representantes fue la que de nuevo frenó la constitucionalización. Desde entonces, no han dejado de proponerse enmiendas que siguen el patrón de la de 1995, la última de ellas, de hecho, en mayo de $2016^{51}$, pero todas sin éxito alguno.

Sin embargo, aunque desde finales de los 70 con el clima de la Revolt Tax no se volvió a impulsar un movimiento destacado como el de entonces por la convocatoria de una convención constitucional, la posibilidad de ésta sigue estando abierta, pues aunque parezca sorprendente, los requerimientos estatales que en su día se elevaron ante el Congreso siguen vigentes. Solo una

${ }^{47}$ David Kyvig, «Refining or Resisting Modern Government? The Balanced Budget Amendment to the U. S. Constitution»: 112-113, sobre la relación de Reagan con la BBR y la historia de la «enmienda consenso».

48 James Poterba, «Do Budget Rules work?», National Bureau of Economic Research, working paper 5550, (1996): 15-25.

49 David Kyvig, ibid.: 121. El programa republicano se llamó «Contract with America».

${ }^{50}$ Algunos abogaban aquí, no obstante, por excluir a la Seguridad Social del cálculo presupuestario para que no se viera nunca afectada por posibles recortes. El Senador Harry Reid fue el que lideró esta propuesta, que en cierta manera debilitaba la BBR.

${ }^{51}$ Puede consultarse en https://www.congress.gov/bill/114th-congress/house-jointresolution/93/text ) Consultado el 3 de diciembre de 2016). 
decisión ex profeso de la asamblea legislativa estatal puede revocarlos, y entre los que así se descartaron y los que posteriormente se elevaron individualmente, a día de hoy sigue habiendo 28 Estados con solicitudes presentadas para la convocatoria de una convención. El mínimo, 34, no está tan alejado, como tampoco lo está la posibilidad misma de que se dé finalmente en los próximos años si el contexto político así lo facilita ${ }^{52}$.

$\mathrm{Y}$ en este debate que parece interminable, de entre todas las enmiendas que se han presentado, la de 1995 ha sido sin duda la más completa y la que más comentarios ha recibido, hasta el punto de haberse convertido en un referente en la materia ${ }^{53}$. De acuerdo con la línea trazada por la «enmienda de consenso» de Hatch, además de la exigencia de un equilibrio presupuestario se establecían mayorías cualificadas en ambas cámaras para la modificación de las bases impositivas y para la autorización de emisión de deuda pública al gobierno federal, blindando así con mayor contundencia el margen de actuación en materia fiscal. Al ser, como decimos, uno de los proyectos más analizados y el que ha sido tomado como parámetro en las enmiendas subsiguientes, lo tomaremos también nosotros como referencia conforme

52 Toda la información puede encontrarse en la página web del movimiento pro-enmienda actual http://bba4usa.org/ (Consultado el 18 de noviembre de 2016). Incluso, ante el vacío jurídico en que caería una posible convención constituyente, el movimiento proconvención ha elaborado un borrador de normas que regularían la misma, y que puede consultarse aquí: http://www.conventionofstates.com/proposed_rules (Consultado el 21 de noviembre de 2016).

53 Texto completo de la enmienda BBR de 1995: SECTION 1. Total outlays for any fiscal year shall not exceed total receipts for that fiscal year, unless three-fifths of the whole number of each House of Congress shall provide by law for a specific excess of outlays over receipts by a roll-call vote. SECTION 2. The limit on the debt of the United States held by the public shall not be increased, unless three-fifths of the whole number of each House shall provide by law for such an increase by rollcall vote. SECTION 3. Prior to each fiscal year, the President shall transmit to the Congress a proposed budget for the United States Government for that fiscal year, in which total outlays do not exceed total receipts. SECTION 4. No bill to increase revenue shall become law unless approved by a majority of the whole number of each House by a roll-call vote. SECTION 5. The Congress may waive the provisions of this article for any fiscal year in which a declaration of war is in effect. The provisions of this article may be waived for any fiscal year in which the United Sates is engaged in military conflict which causes an imminent and serious military threat to national security and is so declared by a joint resolution, adopted by a majority of the whole number of each House, which becomes law. SECTION 6. The Congress shall enforce and implement this article by appropriate legislation, which may rely on estimates of outlays and receipts. SECTION 7. Total receipts shall include all receipts of the United States Government except those derived from borrowing. Total outlays shall include all outlays of the United States Government except for those for repayment of debt principal. SECTION 8. This article shall take effect beginning with fiscal year 2002, or with the second fiscal year beginning after ratification, whichever is later.» 
vayamos desplegando, a continuación, los problemas que presenta la constitucionalización de la estabilidad presupuestaria, al calor, claro está, del debate norteamericano.

\section{LA PROBLEMÁTICA CONSTITUCIONAL DE LA ESTABILIDAD PRESUPUESTARIA}

Tanto el borrador de 1995 y el debate que lo rodeó como las experiencias estatales que ya se habían proyectado a lo largo del siglo XIX en torno a la $\mathrm{BBR}^{54}$, arriba vistas, nos ofrecen un marco único del que poder extraer un análisis de los principales inconvenientes que presenta la constitucionalización de la estabilidad presupuestaria.

La combinación de disciplinas que se da en cualquier estudio sobre la materia, desde el Derecho constitucional a la Economía o la teoría de la Hacienda Pública, no ha coadyuvado precisamente a que el debate sobre el particular pueda centrarse desde categorías jurídicas, y más cuando la mayor parte del mismo siempre gira en torno a la conveniencia económica, o no, de la estabilidad presupuestaria ${ }^{55}$. Los constitucionalistas no suelen, además, abordar cuestiones que rocen la economía, y los economistas, por su parte, desconocen en gran medida el contexto jurídico-constitucional en el que las categorías económicas se desenvuelven, creando ello un vacío de análisis integrales sobre la cuestión ${ }^{5657}$.

A pesar de estas dificultades, pueden esbozarse cinco puntos clave sobre los que versa la mayor parte de la problemática técnico-constitucional, y que ya han sido abordados predominantemente por la academia estadounidense de acuerdo con los intentos de enmienda (o convención) arriba indicados.

${ }^{54}$ Un intento completo de sacar conclusiones desde las experiencias estatales, puede verse en la obra del seguidor de la public choice y de la Economía constitucional, James Poterba. Cfr.: «Balanced Budget Rules and Fiscal Policy: Evidence From the States», National Tax Journal, 48, (1995) y la citada «Do Budget Rules Work?»: 23-26. El autor se muestra siempre partidario de la eficacia de las restricciones institucionales sobre los niveles de déficit y deuda pública.

${ }_{55}$ Para un análisis desde la ciencia política de la conveniencia de la BBR, puede verse William Keech, «A Theoretical Analysis of the Case for a Balanced Budget Amendment», Policy Sciences, 18, n 2, (1985).

56 Theodore Seto, «Drafting a Federal Balanced Budget Amendment That Does What It Is Supposed To Do (And No more),»: 1453.

57 Tamim Bayoumi y Barry Eichengreen, «Restraining Yourself: The Implications of Fiscal Rules for Economic Stabilization», Staff Papers, International Monetary Fund, 42, $\mathrm{n}^{\circ} 1$, (1995). Aquí se hace un análisis de la eficacia que tienen las BBR, incluso, en las políticas anti-cíclicas. 


\section{La definición y el método contable}

De un primer acercamiento a la BBR parece desprenderse una aparente sencillez en la pretensión: evitar que se gaste más de lo que se ingresa en un periodo terminado, requiriendo un equilibrio en las proyecciones de ambas fuentes que suele estar sujeto a una relación numérica o porcentual. Sin embargo, a medida que vamos desentrañando cada concepto y previsión, la tarea se complica y comienza a desplegar un sinfín de dificultades ${ }^{58}$.

El primero de ellos, el más evidente, es la determinación de las cuantías que están en juego. Los métodos de contar y computar los ingresos y los gastos de un Estado no son uniformes, y en ocasiones ni siquiera vienen establecidos o indicados en la propia previsión constitucional de la BBR, como ocurría, de hecho, en el proyecto de enmienda de 1995. Las consecuencias de elegir uno u otro son, además, esenciales para la efectividad misma de la estabilidad presupuestaria. Principalmente existen dos grandes métodos de cálculo: el de contabilidad de caja o efectivo (cash) y el de contabilidad de devengo o acumulación (accrual) ${ }^{59}$. La diferencia entre ambos estriba en la consideración del concreto periodo temporal en que se producen y por ende, se imputan, los gastos o los ingresos. En el método de caja éstos se producen cuando el dinero es gastado o recibido de manera efectiva. El balance se realiza atendiendo a las cantidades que en cada momento salen o entran en la contabilidad, sin contar las obligaciones futuras contraídas. Es, pues, el método más sencillo y popular, generalmente empleado en pequeños negocios. Por su parte, el método de devengo presenta una mayor complejidad pero tiende a reflejar mejor el estado contable de un balance. Los ingresos o gastos se computan desde el momento en el que, como el propio nombre del método indica, se devengan, es decir, cuando las obligaciones comienzan a desplegar efectos aunque no se haya aún recibido o gastado el dinero. Por ejemplo, un fabricante de coches computará como ingresos los coches vendidos, aunque no se hayan realizado todavía las entregas, y como gastos, los pedidos de materiales que sin haberse entregados aún, ya han sido solicitados. Frente al método de caja o cash, el de devengo proporciona una visión más exacta y más a largo plazo del balance y de las consiguientes necesidades presupuestarias, de ahí que sea el preferido por las grandes compañías o el sector financiero.

${ }^{58}$ Raymond Saulnier, «Do We Need a Balanced-Budget Amendment to the Constitution?», Presidential Studies Quarterly, 18, n 1, (1988): 159. El autor resume muy sucintamente en este breve texto el conjunto de dificultades con el que nos encontraremos en las páginas siguientes.

59 James Bowen, «Enforcing the Balanced Budget Rule», 581-584. Aquí analiza los métodos seguidos por el Gobierno Federal y su preferencia por el sistema de caja o cash. 
El proyecto de enmienda de 1995 establecía, en este sentido, que «los desembolsos de cada año fiscal no excederán el total de los ingresos a menos que $4 / 5$ del total de miembros de cada Cámara del Congreso permita por ley un exceso específico» ${ }^{60}$. ¿Qué sistema, por tanto, se había elegido? A pesar de ser tan trascendental la cuestión para la virtualidad de una BBR constitucional, la enmienda, simplemente, la deja abierta ${ }^{61}$. De seguir el de caja, el Congreso podría comprometerse, por ejemplo, con gastos gigantescos para los años siguientes sin que éstos se computaran en la BBR, quedando así fuera de la restricción constitucional hasta que fueran efectivamente desembolsados. Como dice Seto, «quizá la más flagrante inexactitud de las obligaciones impagadas del método de caja es...ignorarlas $\rangle^{62}$.

En tanto el sistema de caja no refleja el estado de las cuentas a largo plazo, al centrarse únicamente en lo pagado y recibido en un periodo concreto, pueden producirse serias disfuncionalidades a la hora de planificar los presupuestos $^{63}$; disfuncionalidades que podrían ser enmendadas en un sistema de devengo que recogiera todas las obligaciones contraídas y fuera capaz, además, de desplegarlas con exactitud en los distintos periodos presupuestarios. Un sistema de caja, además, también desvirtuaría los superávits acumulados en años precedentes, al no saberlos computar eficazmente, como de hecho, ya ha ocurrido en la aplicación de algunas BBR estatales.

El paradigma de los problemas interpretativos que pueden concurrir en la constitucionalización de la estabilidad presupuestaria se dio, en efecto, en el Estado de Idaho con la construcción de una cárcel en un condado. Éste había ido acumulando ingresos tributarios durante sucesivos periodos fiscales para

${ }^{60}$ «Outlays for any fiscal year shall not exceed total recepits unless three-fifths of the whole number of each House of Congress shall provide by law for a specific excess of outlays over vote». Traducción propia.

${ }^{61}$ Theodore Seto, ibid.: 1482 y ss. El autor es partidario, inequívocamente, de un método de devengo.

${ }^{62}$ «Perhaps the most flagrant inaccuracy of the cash method umpaid obligations is... it ignores them», ibid.: 1483. Traducción propia.

${ }^{63}$ Pongamos un ejemplo. Para financiar un proyecto, al Gobierno o al Congresose le presentan dos posibles soluciones: financiarlo entero ese año con un coste de 10 millones de dólares, que garantizarían la vigencia del proyecto durante 10 años, o financiarlo con 2 millones de dólares que garantizarían la viabilidad del proyecto para ese mismo año. Como el sistema de caja no recoge el largo plazo, sino que se centra únicamente en lo pagado y en lo recibido en un periodo concreto (en un año fiscal, en este caso), el legislador o el gobernante tendería a elegir la última opción (2 millones de dólares año), por suponer menor aumento del déficit/gasto en su año fiscal, a pesar de que a largo plazo la primera opción sería mucho más económica (1 millón de dólares año). Un método de devengo, por el contrario, sería capaz de imputar correctamente la cantidad devengada a largo plazo y repartirla por el periodo subsiguiente en el que el programa se va a aplicar, sin necesidad de imputar los 10 millones de dólares al primer año. 
la construcción de la misma, y cuando comprobó que ya eran suficientes, aprobó una partida presupuestaria para comenzar el proyecto. Para sorpresa de las autoridades del condado, la partida fue demandada ante la Corte Suprema del Estado por vulnerar la BBR que figura en su Constitución, por cuanto del análisis mediante contabilidad de caja del periodo presupuestario en el que la partida debía aplicarse, resultaba que ésta desequilibraba el balance al ser superiores los gastos que los ingresos (de ese periodo). Sin necesidad de financiarse mediante deuda y sin incurrir en déficit, el condado era demandado por incumplir la estabilidad presupuestaria. Utilizando una contabilidad de devengo no se suscitaría siquiera ninguna posibilidad argumental, por cuanto los superávits acumulados podrían computarse en los años siguientes como ingresos, como así hizo finalmente la Corte, ampliando interpretativamente el concepto de revenues (ingresos) que figuraba en la Constitución estatal y permitiendo una mejor planificación a largo plazo de la capacidad presupuestaria sin contravenir la BBR constitucional ${ }^{64}$.

La concreción del método específico de contabilidad, como vemos, es esencial en cualquier aplicación de la estabilidad presupuestaria y en la realización misma de su virtualidad jurídica. Sin embargo, si se eligiera el método de devengo, sin duda el más completo y eficaz, se haría necesario la supervisión de las cantidades devengadas y su reparto temporal a lo largo de los subsiguientes periodos fiscales, y ahí reside, de nuevo, otro problema. ¿Quién lo haría? Si fuera el Congreso, o incluso el Presidente, éstos serían jueces y partes, al ser ellos mismos los emisores principales de los presupuestos, pudiendo quedar desvirtuada jurídicamente la fuerza vinculante supralegal de la previsión constitucional. De ahí que haya autores que aboguen por la creación de agencias independientes para la determinación de los devengos, aunque éstas puedan presentar una problemática mayor aún, dada su falta de legitimidad democrática en la toma de decisiones sobre un campo de política económica tan relevante ${ }^{65}$.

${ }^{64}$ El caso es relatado en Donald Tobin, «The Balanced Budget Amendment: Will Judges Become Accountants?», Journal of Law and Policy, $\mathrm{n}^{\circ} 12$, (1996): 157 y 158. La misma situación puede darse en cuanto a los gastos. La práctica común en Estados Unidos de crear trust funds o fondos fiduciarios públicos, que sirven para acumular durante el crecimiento económico cantidades de dinero que son desembolsadas en situaciones de crisis en beneficio de los fiduciarios (fondos de desempleo, vg), podría aumentar considerablemente la disparidad de un presupuesto para un periodo concreto si se siguiera el método de caja. Aquí, algunas decisiones en las Cortes estatales han sido más restrictivas, como en Bonemo v. State of North Carolina, donde la Corte de Apelaciones del Estado entendió que los gastos (expenditure) han de computarse conforme se desembolsan, siguiendo el sistema de cash, a pesar de sus inconvenientes.

${ }_{65}$ Theodore Seto, ibid.: 1493. El presupuesto del gobierno federal en 2015 fue, por ejemplo, de 1.010.000.000 millones de dólares. 


\section{Flexibilidad y transitoriedad}

La posibilidad de que la economía misma del país se desestabilice como consecuencia de una repentina entrada en vigor de la BBR también ha de contemplarse en cualquier previsión constitucional. Exigir que en el año en el que se aprueba la enmienda constitucional, por ejemplo, se cumpla ya con los rigores del equilibrio presupuestario sin atender a la diversidad de situaciones que pueden heredarse de los años anteriores, podría agravar aún más una recesión económica o, directamente, provocarla. Siendo consciente de ello, la enmienda de 1995 contemplaba una vacatio legis hasta 2002, tiempo suficiente, se estimó, para que pudiera alcanzarse sin perentoriedades el equilibrio presupuestario y que éste se mantuviera, en adelante, estable ${ }^{66}$. Sin embargo, la necesidad de establecer periodos de transitoriedad no se predicaría solamente de la entrada en vigor del texto, sino también de las posibles suspensiones ulteriores de sus previsiones (guerras, por ejemplo), algo que no hacía el texto del 95.

Como decimos, también se ha de prever situaciones en las que la regla de gasto se suspenda para permitir desembolsos extraordinarios ante la urgencia, y la propia extraordinariedad, de la coyuntura. Conflictos bélicos o graves recesiones económicas podrían remover las exigencias de la BBR y permitir así específicas medidas anticíclicas de estímulo o gastos urgentes en materia militar ${ }^{67}$. De nuevo, no obstante, el problema aparece en la determinación de quién ha de ser el que considere que las circunstancias habilitantes se cumplen, y más habida cuenta del alto número de conflictos militares y crisis económicas que han atravesado, con distinta intensidad, la historia reciente de los Estados Unidos. En el caso de las guerras, por ejemplo, la extrema indefinición de su propia naturaleza jurídica en las relaciones internacionales actuales podría dar pie a interpretaciones excesivamente flexibles de la previsión constitucional y, finalmente, a la anulación de su propia virtualidad.

Otra cuestión que se abre, quizá de naturaleza más técnica pero no por ello menos importante, viene dada por las propias características del ajuste temporal de la estabilidad presupuestaria. Ésta no se aplica sobre situaciones pasadas, sino futuras, y sobre la base de previsiones de gasto e ingresos que pueden variar en grado sumo dada su flexibilidad ${ }^{68}$. Cambios repentinos en el ciclo económico, o en la a veces impredecible inflación, pueden modificar

${ }^{66}$ Sección 8 del borrador: «This article shall take effect beginning with fiscal year 2002 , or with the second fiscal year beginning after ratification, whichever is later».

${ }^{67}$ Desde una perspectiva economicista y liberal sobre las consecuencias de una BBR sobre las políticas anti-cíclicas puede verse, Paolo Manasse, «Deficit Limits, Budgets Rules and Fiscal Policy», IMF Working Paper, (2005).

68 James Bowen, ibid.: 854-856. 
sustancialmente los ingresos (o los gastos) de un gobierno dentro de un mismo periodo fiscal, y convertir las predicciones anteriores en, cuanto menos, inexactas ${ }^{69}$.

\section{Contenidos accesorios... ¿necesarios?}

La segunda sección del borrador de enmienda de 1995 incorporaba la siguiente restricción: «El límite sobre la deuda de los Estados Unidos en poder del público no se incrementará a menos que $3 / 5$ del número total de miembros de cada Cámara establezca por ley tal incremento por votación nominal» ${ }^{70}$. Es decir, se establece una limitación a la emisión de deuda que solo puede ser levantada mediante una mayoría cualificada. ¿Constituye ello, sin embargo, parte de la estabilidad presupuestaria? Stricto sensu no, por cuanto la consecución de un déficit cero puede perfectamente darse al mismo tiempo que se mantienen niveles de deuda pública, la cual sirve, precisamente, para financiar dicho déficit. No obstante, en tanto la estabilidad presupuestaria intenta desplegar sus efectos de cara al futuro, se ha venido admitiendo que en paralelo se establezcan límites a los niveles de deuda, generalmente indexados al PBI, para evitar que el equilibrio presupuestario decaiga por excesivas obligaciones financieras que tarde o temprano tendrán que repercutir en los déficits sucesivos. De hecho, la introducción de esta perspectiva a largo plazo, conocida como «Sostenibilidad financiera», se ha incardinado tanto en el concepto de estabilidad presupuestaria que ambos tienden a confundirse, incluso en el seno de la doctrina ${ }^{71}$.

Cuestión distinta es la tendencia a aprovechar la constitucionalización de la estabilidad presupuestaria para incorporar, al mismo tiempo, reglas accesorias que restrinjan el margen de maniobra tributario del Estado. Para equilibrar el presupuesto no tiene por qué acudirse siempre a los recortes en el gasto, pues los incrementos fiscales pueden ayudar a la balanza. Empero, como vimos en páginas precedentes, uno de los postulados de la Economía constitucional era el blindaje de los impuestos mediante mayorías cualificadas para evitar así

${ }^{69}$ Theodore Seto, ibid:: 1506. El autor propone, nuevamente, una agencia independiente para que se encargue de hacer tales previsiones.

70 «The limit on debt of Unites States held by the public shall not be increased, unless three-fifths of the whole number of each House shall provide by law for such increase by rollcall vote». Traducción propia.

${ }^{71}$ En general, en el mundo anglosajón la distinción sigue manteniéndose en el ámbito académico, pero en Europa se ha desfigurado por completo a través de la reciente constitucionalización de los mecanismos de gobernanza económica desde el proceso de integración. Curiosamente, aunque la reforma constitucional en España incorpora ambas dimensiones en el mismo precepto renovado, el artículo 135, la Ley Orgánica de desarrollo (de Estabilidad Presupuestaria y Sostenibilidad Financiera) mantiene la diferencia. 
subidas en los tan temidos por ellos mecanismos de redistribución. En este sentido, la enmienda de 1995 reflejaba, conscientemente o no, tal postulado al exigir un $60 \%$ de apoyo en las dos cámaras del Congreso para elevar los impuestos federales. Ello conllevaría, en el marco del complejo sistema institucional y de partidos norteamericanos, una petrificación del statu quo fiscal y un aumento considerable de la dificultad, ya existente, de llevar a cabo efectivas medidas redistributivas, pues a este límite de ingresos hemos de sumar el techo «por arriba» de la deuda pública y la exigencia, envolvente, de la estabilidad presupuestaria $^{72}$. Como se indica por parte de la doctrina, esta previsión de mayorías cualificadas para elevar los impuestos federales no es connatural a la estabilidad presupuestaria, y ni siquiera tiene por qué aunar el mismo consenso que ésta última, a pesar de que en el proyecto de 1995, y en los sucesivos, fuera siempre aneja ${ }^{73}$.

Siguiendo esa estela de la Economía constitucional en cuanto a mayores restricciones constitucionales del poder tributario del Estado, algunos autores como Kiewiet y Szakaly, defienden también la conveniencia de constitucionalizar la necesidad de referéndums a nivel nacional para elevar los límites de deuda, en la creencia de que los mecanismos de democracia semidirecta sirven mejor para frenar las tendencias expansionistas, inmanentes, del Estado y su Administración ${ }^{74}$.

${ }^{72}$ Harvard Law Association, «The Balanced Budget Amendment: An Inquiry into Appropriateness», Harvard Law Review, 96, $\mathrm{n}^{\circ}$ 7, (1983): 1606 y ss.

73 Theodore Seto, ibid.: 1475 y 1476. Buchanan, por su parte, abstrayéndose de la realidad político-institucional de los Estados Unidos, defiende tal previsión como una medida que no desvirtúa la capacidad tributaria de la Federación al considerarla meramente procedimental, y no substancial. James Buchanan, «Clarifying Confusion About the Balanced Budget Amendment», National Tax Journal, 48, $\mathrm{n}^{\circ}$ 3, (1995): 350. Dice: «The essential distinction that must be made is that between a rule that acts on the procedures through wich participants are allowed to reach and to carry out decisions and a rule that acts directly on the outcomes that any such decisions might describe. A simple example: a rule that all motor vehicles must drive on the right side of two-way roads in the USA is procedural [...] In the context of democratic politics, most of the rules that we normally classify to be constitutional are procedural» (La distinción esencial que debe ser hecha es entre una regla que actúa sobre los procedimientos a través de la cual se permite a los participantes alcanzar y llevar a cabo decisiones, y una regla que actúa directamente sobre los objetivos que tales decisiones podrían describir. Un ejemplo simple: una regla que establezca que todos los vehículos a motor deben conducir por la derecha en la carretera de dos vías en Estados Unidos es procedimental [...]. En el contexto de las políticas democráticas, la mayoría de las reglas que nosotros normalmente clasificamos como constitucionales son procedimentales). Traducción propia.

${ }^{74}$ Roderick Kiewiet y Kristin Szakaly, «Constitutional Limitations on Borrowing: an Analysis of State Bonded Indebtedness», The Journal of Law, Economics and Organization, 12, n 1, (1996): 93. Según ellos, además, los mecanismos de democracia semidirec- 


\section{La evasión (¿legal?) de la estabilidad presupuestaria}

Como hemos visto, el objetivo principal de elevar a rango constitucional la BBR es dotar a ésta de una fuerza vinculante supralegal, por encima de las propias instituciones que protagonizan el proceso presupuestario y de, incluso, las mayorías sociales cambiantes que se alternan en los poderes constituidos. La preocupación de que por parte de éstos la regla no se cumpla a través de instrumentos de evasión, más o menos sofisticados, ha de ser, por ende, esencial en la garantía misma de la estabilidad presupuestaria ${ }^{75}$. Y de nuevo, el marco de los Estados federados en el que ésta ya ha sido constitucionalizada mayoritariamente nos proporciona un excelente campo de estudio y análisis ${ }^{76}$.

\section{Special funds y building authorities}

Los fondos especiales son instrumentos jurídicos muy populares en los Estados norteamericanos para la financiación de proyectos concretos, generalmente obras e infraestructuras de gran envergadura, para los cuales las cantidades de tales fondos están estrictamente reservadas. Generalmente, éstos suelen estar financiados por la emisión de deuda propia, la participación en ellos del sector privado o la adscripción de los ingresos de determinados

ta que existen a nivel estatal han servido mejor para conseguir estables equilibrios presupuestarios que la introducción de mayorías cualificadas. Sobre la defensa de tales mecanismos, aunque traslada al sui generis sistema democrático suizo, Cfr.: Lars Feld y Gebhard Kirchgässner, "On the Effectiveness of Debt Brakes: The Swis Experience», Center for Research in Economics, Management and the Arts, Working Paper, $\mathrm{n}^{\circ} 21$, (2006): 3 y 4. Defienden esta medida en su trabajo porque, de sus análisis sobre los datos comparativos desde la década de los 60 hasta principios de los 90 , se desprende según ellos que los Estados que tienen constitucionalizada la necesidad de referéndum para elevar los niveles de deuda, emiten menos y tienen sus cuentas, por ende, más «saneadas». Critican, al mismo tiempo, la ineficiencia del requerimiento a tal fin de mayorías cualificadas en los parlamentos. Lee Moak, Municipal Bonds: Planning, Sale, And Administration, (Chicago: Municipal Finance Officers Association, 1982): 114. Según el autor, «la historia de la deuda pública en los Estados Unidos a todos los niveles tiende a mostrar que el electorado es financieramente más conservador que sus representantes en el gobierno» (The history of public debt in the United States at all levels tends to show that the electorate is financially more conservative than are its representatives in government). Traducción propia.

${ }_{75}$ No obstante, algunos sostienen que lo verdaderamente determinante en cuanto al cumplimiento de la estabilidad presupuestaria no es el marco de restricciones que se proyecte desde la Constitución, sino la cultura política y el sistema de partidos del país en cuestión. Vid. Aaron Wildavsky, «A Cultural Theory of Expenditure Growth and (Un) balanced Budgets», Journal of Public Economics, 28, nº 3 (1985): 349-357.

${ }^{76}$ Anita Krishnakumar, «In defense of the debt limit statute», 175-180. 
impuestos estatales para su cometido. A pesar de ello, es una práctica continuada en los Estados la exclusión de tales cantidades del cómputo general presupuestario, quedando por tanto también fuera de las restricciones de la $\mathrm{BBR}^{77}$. Su utilización masiva, incluso para afrontar gastos corrientes, puede suponer una evasión inconstitucional de la estabilidad presupuestaria.

Asimismo, y muy conectadas a los special funds por la similitud de su funcionamiento y naturaleza, nos encontramos las hoy famosas building authorities, creadas a principios del siglo XX por los Estados para financiar grandes infraestructuras ${ }^{78}$, y que, dotadas de autonomía financiera, son nutridas sin embargo, y casi en su totalidad, por deuda pública respaldada por los Estados. A diferencia de las operating authorities, que se autofinancian una vez que la infraestructura ha sido construida a través de la explotación comercial y privada de su uso, las building apenas dejan margen de acción para los inversores privados, que sólo pueden obtener beneficios mediante el reintegro de los intereses de la deuda comprada a tales instituciones ${ }^{79}$.

Junto con los special funds, estas instituciones suelen ser los instrumentos más utilizados para la evasión de las BBR estatales. Y es que, a pesar de que la deuda emitida está respaldada por los presupuestos estatales, ésta no suele computar en los mismos y es administrada en ocasiones, además, bajo condiciones de opacidad escudadas en la autonomía de tales organismos $a d h o c^{80}$.

\section{Deuda a muy corto plazo}

Tal y como hemos explicado, la BBR se aplica sobre periodos concretos de tiempo, generalmente sobre los años fiscales, por lo que se posibilita que

${ }^{77}$ Werner Heun, «Balanced Budget Requirements and Debt: Brakes feasibility and Enforcement», German Economic Review, 15, nº 1, (2014): 105.

${ }^{78}$ Sobre la creación de authorities por parte de los Estados para que administren fondos especiales no sujetos a las limitaciones de deuda de las BBR estatales, Beberly Bunch, «The Effect of Constitutional Debt Limits on State Governments' Use of Public Authorities», Public Choice, 68, n 1/3, (1991): 57-69. El autor hace un análisis de los datos que proporcionan diversas fuentes para concluir que, conforme son más estrictas las restricciones constitucionales de BBR tanto sobre la deuda como sobre el déficit, los Estados crean más medios alternativos, como estas authorities, para evadirlas. Al respecto, el estudio de Morris, aunque escrito a finales de los 50, no ha perdido vigencia, y sigue constituyendo una fuente importante a la hora de analizar el fenómeno y sus orígenes, vide. Robert Morris, «Evading Debt Limitations with Public Building Authorities: The Costly Subversion of State Constitutions», The Yale Law Journal, 68, $\mathrm{n}^{\circ}$ 2, (1958). Las authorities pueden también recibir otros nombres, como boards, commissions, agencies...

${ }_{79}$ La primera authority destacada fue la The Port of New York Authority, creada en 1921. Para un análisis de las mismas, Robert Morris, ibid.: 235-236, y 250 y ss.

${ }^{80}$ Roderick Kiewiet y Kristin Szakaly, «Constitutional Limitations on Borrowing: an Analysis of State Bonded Indebtedness», 69-71. 
los Gobiernos jueguen con los plazos para emitir deuda dentro de ese periodo que, venciendo antes de que finalice el mismo, no repercuta en momentos posteriores. Esta operación, denominada como Short-Term Borrowing, ha sido muy utilizada sobre todo en aquellos Estados donde la regla de estabilidad presupuestaria se aplica más restrictivamente. En Nueva York ha llegado a ventilarse judicialmente en los casos Wein v. State I y II, donde la Corte de Apelaciones del Estado no consideró inconstitucionales tales operaciones siempre y cuando las predicciones de gastos e ingresos en las que se encuadraban no fueran negligentes o «excesivamente» optimistas, por cuanto ello podría provocar el aplazamiento de la deuda a corto plazo y su «estiramiento» a años sucesivos, incumpliendo así, pues, la BBR constitucionalizada ${ }^{81}$.

De este modo, existen multitud de instrumentos que pueden ser utilizados por los poderes constituidos para evadir el mandato que les impone el poder constituyente, o el poder de reforma constitucional, y saltarse la regla de la estabilidad presupuestaria a través de artefactos de, en ocasiones, compleja articulación jurídica. Existen, por supuesto, más cauces y lagunas jurídicas que pueden ser utilizados a tal fin, pero aquí hemos analizado sucintamente los más populares y los que más impacto tienen a la hora de analizar la efectividad de una $\mathrm{BBR}^{82}$.

\section{EL PROBLEMA DE LA EJECUTORIEDAD: ¿JUECES HACIENDO CUENTAS?}

Las causas de llevar a la Constitución la estabilidad presupuestaria no sólo se proyectan ante el temor de su incumplimiento mediante instrumentos de evasión, sino también sobre el contenido mismo de la ejecutoriedad judicial y de la pervivencia, en última instancia, de su naturaleza vinculante. Ríos de tinta se han vertido sobre la posibilidad de que los tribunales de justicia intervengan en la potestad presupuestaria en caso de que se incumpla una BBR constitucional, pues en buena medida la eficacia jurídica de ésta depende de ello. De ahí que, dada la relevancia de la cuestión que se abre en

${ }^{81}$ Donald Tobin, «The Balanced Budget Amendment: Will Judges Become Accountants?», 160 .

${ }^{82}$ Los lease agreement, por ejemplo, constituyen otro instrumento off-budget de evasión cuya constitucionalidad ha llegado también a las Cortes estatales. Muy resumidamente, consisten en la celebración de contratos entre los poderes públicos y terceros para que éstos financien un proyecto a cambio de una renta periódica, con opción final de compra o aprovechamiento comercial del resultado del proyecto. En casos como Dieck. $V$. Unified School District of Antigo, que fue ventilado por la Corte Suprema de Wisconsin, se ha establecido que dichos acuerdos, a pesar de constituir compromisos financieros, no vulneran la balanced budget por existir cláusulas de terminación que garantizan cierta discrecionalidad en el cumplimiento a los Estados o autoridades públicas. 
torno a la ejecutoriedad, la analicemos aparte para garantizar de este modo una mayor dedicación a su particular problemática.

El precompromiso elsteriano del que nos hablaba Buchanan sólo puede ser garantizado si la estabilidad presupuestaria se juridifica en un ámbito indisponible para quienes tienen la posibilidad de incumplirla. Las cuerdas que atan al Ulises ante las sirenas, para ser eficaces, deben ser lo suficientemente férreas como para que el propio encadenado no pueda desatarse. La ineficacia, en este sentido vinculante, de las disposiciones meramente legislativas ${ }^{83}$ explica así la necesidad, por parte de sus defensores, de constitucionalizar la $\mathrm{BBR}^{84}$. Para ser jurídicamente vinculante se precisa un control judicial ulterior que haga verdaderamente efectiva su fuerza constitucional aun por encima de la voluntad de los poderes constituidos, pues ésa es, precisamente, la función de la jurisdicción constitucional. Sin embargo, la dificultad de dicha tarea y las inquietudes políticas que despierta complican la extensión de dicha jurisdicción a la estabilidad presupuestaria y sus reglas. Y, de nuevo, el proyecto de enmienda de 1995 y las experiencias estatales en la materia nos proporcionan el marco idóneo para el estudio de tal problemática $^{85}$.

${ }^{83}$ Como recordábamos con anterioridad, en 1985 se aprobaría la famosa GrammRudman-Hollings Balanced Budget and Emergency Deficit Control Act, con una posterior adenda en 1987, la Reaffirmation Act, para intentar combatir el déficit público a largo plazo. La ley alargaba la perspectiva de los presupuestos, permitía establecer objetivos de déficit, interesaba al Presidente enviar al Congreso presupuestos equilibrados...etc. Para un análisis de la norma puede verse Yilin Hou y Daniel Smith, «Framework for Understanding State Balanced Budget Requirement Systems: Reexamining Distintive Features and an Operational Definition», Public Budgeting and Finance, 26, n 3, (2006): 43; y Sung Hanm, Mark Kamlet, David Moewry y Tsai Tsu Su, «The influence of the GrammRudman-Hollings Act on Federal Budgetary», Journal of Policy Analisys and Manageme, $11, \mathrm{n}^{\mathrm{o}} 2$ 2, (1992). Estos últimos autores defienden la misma como instrumento efectivo para frenar la tendencia a la expansión fiscal de la Federación.

${ }^{84}$ En este sentido, Thomas Schelling, siguiendo a la public choice de Buchanan, realiza una metáfora similar sobre la constitucionalización de la BBR, pero llamando al precompromiso self-command. Thomas Schelling, Choice and consequence, (Cambridge: Harvard University, 1984). El propio Elster comentaría esta aportación en John Elster, «Review of Schelling: Choice and Consequence», Journal of Economic Behavior, $\mathrm{n}^{\circ}$ 6, (1985). Buchanan y Wagner, siguiendo la estela de la metáfora elsteriana, llegan a hacer la analogía con los borrachos que restringen a sí mismos su voluntad. James Buchanan y Richard Wagner, Democracy in Deficit, (New York: Academic Press, 1977): 159.

85 Theodore Seto, «Drafting a Federal Balanced Budget Amendment That Does What It Is Supposed To Do (And No more)», 1471. Aquí indica que en 1982, un informe de la Oficina Presupuestaria del Congreso había concluido que en casi todos los Estados las previsiones constitucionales de BBR no habían evitado el aumento de deuda pública durante los 20 años precedentes. Como diría la propia Corte Suprema del Estado de Wisconsin: «The history of the Wisconsin constitutional provision concerning municipal debt 
Tal y como ya hemos explicado, para equilibrar un presupuesto se pueden seguir dos caminos: o aumentar los ingresos o recortar el gasto público. $\mathrm{Si}$, mediando una BBR constitucional ya en vigor, el Congreso no aprueba un presupuesto equilibrado donde los gastos no superen a los ingresos... ¿puede la Corte Suprema de los Estados Unidos, en su función de control jurisdiccional de constitucionalidad, hacer cumplir la BBR siguiendo tales caminos?

Los detractores de que la justicia constitucional pueda intervenir directamente en los presupuestos del Estado arguyen que ello la adentraría en el campo de la discrecionalidad política, alejándola de la neutralidad ínsita a su naturaleza, y obligándola a tomar decisiones sobre materias que, a priori, desconoce. En efecto, no es extraño entre la doctrina norteamericana denunciar la falta de habilidades en materia económica de los jueces, lo que parecería ser un inconveniente grave para remediar el incumplimiento de una $\mathrm{BBR}^{86}$. Sin embargo, otros autores como Bowen destacan que la Corte Suprema ya realiza juicios en materia económica (caso de grandes rescates financieros o leyes anti-trust), y que la vaguedad de los conceptos indeterminados que rodean a la estabilidad presupuestaria no es menor que los que rodean a derechos fundamentales tan abiertos a interpretación como la libertad de expresión ${ }^{87}$.

No obstante, aun admitiendo que la ausencia de conocimientos en técnica económica no sea un obstáculo para proyectar la función jurisdiccional sobre la BBR, quedaría por despejar la primera y más acuciante cuestión, la de la discrecionalidad de naturaleza política que tendrían que revestir las decisiones de la Corte Suprema. En caso de intervenir en los presupuestos para introducir recortes que los equilibre... ¿dónde se aplicarían? ¿En gasto en defensa o en sanidad? Cualquier decisión comportaría, necesariamente, una toma de posición política que puede reflejar, a su vez, distintas concepciones ideológicas, con el daño que ello conllevaría para el Estado de Derecho y la división de poderes. Y es aquí, en el esquema clásico de tripartición y en el célebre sistema de checks and balances norteamericano, donde autores como

manifests both and abhorrence for public debt and a willingness to increase the debt limit, particularly for school purposes». Cit. en Donald Tobin, «The Balanced Budget Amendment: Will Judges Become Accountants?». 155. Sobre las experiencias estatales en general, Kenneth Kirkland, «Creative accounting and short-term debt: State responses to the deficit threat», National Tax Journal, 36., nº 3, (1983); o Daniel Suits y Ronald Fisher, «A Balanced Budget Constitutional Amendment: Economic Complexities and Uncertainties», National Tax Journal, 38, nº 4, (1985).

${ }^{86}$ Theodore Seto, ibid.: 1514 y Werner Heun, ibid.: 110 y 111.

87 James Bowen, «Enforcing the Balanced Budget Rule», Seton Hall Constitution, 590-593 y 607. Él mismo reconoce después, sin embargo, que desde el prisma de la teoría política y democrática es difícil defender la posibilidad de que la Corte Suprema intervenga directamente en la reelaboración de unos presupuestos. 
Grosthwait destacan los peligros que la ejecutoriedad judicial de la BBR podría conllevar, llegando directamente a afirmar que «la dificultad central de un mandato para remediar violaciones a la enmienda es su incompatibilidad con la separación de poderes ${ }^{88}$. Hamilton, en el número 78 de El Federalista, alertaba en este sentido sobre posibles extralimitaciones del poder judicial, que no ha de tener influencia «ni sobre la espada ni sobre la bolsa; ni sobre la fuerza o la riqueza de la sociedad, no pudiendo tomar ninguna resolución activa sobre las mismas. $\rangle^{89}$.

Las decisiones sobre la «bolsa», sobre la política económica, tributaria y presupuestaria, han de tomarse por cuerpos legitimados políticamente y respaldados por las mayorías cambiantes, no por órganos cuya naturaleza misma es contramayoritaria y jurídica, y cuya defensa de la legalidad ha de sustanciarse procedimentalmente para evitar la arbitrariedad y garantizar su neutralidad. Si la Corte Suprema tuviera que conocer de las medidas concretas que se necesitarían llevar a cabo para equilibrar un presupuesto, se vería en la diatriba de decidir sobre la localización de sus variables, de los ingresos y los gastos, entrando así en el campo mismo de la administración de los fondos públicos y en la gestión que de ellos hacen las instituciones federales ${ }^{90}$.

Ahora bien, abstrayéndonos de tales inconvenientes, que se predican esencialmente de la teoría democrática y política, y admitiendo que la Corte Suprema pudiera aplicar decisiones directas en materia presupuestaria para hacer efectiva la BBR, la cuestión jurídico-técnica no deja de ser, cuanto menos, problemática.

La Corte Suprema ha tenido la posibilidad de perfilar la doctrina de la «cuestión política» en casos como Baker v. Car (1962) o United States v. Muñoz-Flores (1990), donde intentó definir lo que era materia susceptible de

${ }^{88}$ «The central difficulty with and injuction to remedy Amendment violations is incompatibility with the separation of power». Gay Crosthwait, «Article III: Problems in enforcing the Balanced Budget Amendtment», Columbia Law Review, no 83, (1983): 11. Traducción propia.

89 «Has no influence over either the sword or the purse; no direction either of the strength or of the wealth of the society; and can take no active resolution whatever». Traducción propia.

${ }_{90}$ Bowen es de la doctrina minoritaria que apoya la posibilidad de que la Corte apruebe remedios directos contra presupuestos inconstitucionales. Así lo argumenta en James Bowen, «Enforcing the Balanced Budget Rule», 611-618. Aparte, y como indica Crosthwait, pervivirían una serie de inconvenientes técnicos cuya solución no está clara. ¿Quiénes serían los sujetos pasivos de las demandas judiciales? ¿Quiénes tendrían que personarse en el proceso? ¿Solo los representantes que hayan votado a favor del presupuesto supuestamente inconstitucional, o todos? Gay Crosthwait, ibid.: 8 . El autor apunta a que durante más de cuarenta años, la opinión autorizada del que fuera Chief Justice de la Corte, Hughes, se decantaba por que los jueces no tuvieran capacidad de decisión alguna sobre materias de naturaleza económica. 
ser judicializada y lo que, en virtud de su naturaleza meramente política, no podría ser analizado bajo el prisma jurisdiccional. ¿Podría ser, pues, aplicable esta doctrina a la estabilidad presupuestaria constitucionalizada? La respuesta no es sencilla, ya que la utilización de tal doctrina ha sido bastante discrecional en la jurisprudencia de la Corte y no son raras las ocasiones en que aquélla no se ha aplicado en materia económica, como en Bowsher v. Synarm, donde directamente se enjuiciaron cuestiones de relevancia presupuestaria ${ }^{91}$. Por ello, parte de la academia sostiene que la compleja y a veces resbaladiza elaboración jurisprudencial de la «cuestión política» no constituiría freno alguno para conocer de la $\mathrm{BBR}^{92}$.

En el caso de los Estados, existen decisiones en ambas direcciones por parte de sus respectivos tribunales, aunque la mayoría suele concordar en la inconveniencia de la intromisión judicial. Así, en Bishop v. Governor, la Corte Suprema de Maryland rechazó una demanda interpuesta contra el Gobernador del Estado con base en su supuesta negligencia a la hora de realizar la estimación de ingresos, lo que podría provocar el incumplimiento subsiguiente de la BBR de la Constitución estatal ${ }^{93}$. En Board of Education of the Township of Fairfield v. Jean, donde se demandaba la anulación de recortes presupuestarios, la Corte Suprema del Estado llegó a afirmar que constituye «un raro caso el que el poder judicial tenga algún rol constitucional en la realización de las partidas presupuestarias $\rangle^{94}$.

Pero no todos los tribunales estatales han sido de ese parecer. Durante el debate de la enmienda de 1995 se blandieron, principalmente, dos sentencias que daban cobertura a la posibilidad de control jurisdiccional de la BBR al haber amparado decisiones directas en materia presupuestaria: Missouri $v$. Jenkins y Flast v. Cohen ${ }^{95}$. En el primer caso, la Corte Suprema de Kansas ordenó, sin intermediación, un incremento de los impuestos estatales para financiar las políticas educativas de no segregación; y en el segundo, la propia Corte Suprema a nivel federal admitió a trámite una demanda de inconstitucionalidad de varios contribuyentes sobre determinados gastos presupuestarios, permitiendo que aquéllos se personaran ante el alto tribunal

${ }^{91}$ Donald Tobin, «The Balanced Budget Amendment: Will Judges Become Accountants?», 191.

${ }_{92}$ Neil Kinkopf, «The Balanced Budget Amendment: A Threat to the Constitutional Order», Georgia State University Publications, 11, nº 1, (2011): 6 y 7.

93 Werner Heun, «Balanced Budget Requirements and Debt: Brakes feasibility and Enforcement», German Economic Review, p. 111.

94 «It is a rare case-and the present case is most certainly not one of them-in which the judiciary has any proper constitutional role in making budget allocations.» Donald Tobin, ibid.: 171 Traducción propia.

95 Sentencias criticada en Neil Kinkopf, ibid.: 9. 
siempre y cuando mediara un vínculo entre su estatus como contribuyentes y la legislación recurrida (standing) ${ }^{96}$.

Estos dos precedentes son los que, en buena medida, fueron blandidos por los detractores del control jurisdiccional en el debate de 1995, frente a la posibilidad abierta de que la Corte Suprema tuviera la última palabra en materia presupuestaria bajo el amparo de la $\mathrm{BBR}^{97}$. Ante tal incertidumbre, ante la posibilidad de que el balance of power estadounidense se decantara por la Corte Suprema, decían, y que un renovado activismo judicial tuviera en sus manos la política presupuestaria ${ }^{98}$, varios senadores intentaron introducir una proposición específica en el borrador de 1995 que prohibiera, taxativamente, la intromisión del alto tribunal. La proposición, planteada finalmente por el senador Danforth, establecía: «El poder de cualquier Corte de decidir conforme a cualquier caso o controversia que se plantee al amparo de este artículo no se extenderá a ordenar ningún remedio, a no ser que un juicio declarativo o tales remedios sean específicamente autorizados en la legislación que desarrolle esta sección $\rangle^{99}$.

Es decir, se anulaba la facultad de la Corte de actuar directamente sobre los presupuestos (incrementando impuestos, recortando gastos, o ambas medidas a la vez), pero se permitía en última instancia que se emitieran juicios declarativos. La distinción es relevante, por cuanto éstos, aunque no tengan una incidencia directa en los presupuestos, sirven para interpretar y aclarar la disposición constitucional en todas sus proyecciones. Mediante ellos, por ejemplo, la Corte podría declarar que determinados instrumentos de evasión de la BBR creados por el Congreso, como los que hemos ya analizado más arriba, son inconstitucionales y prohibir, por ende, su práctica. Asimismo, siguiendo la práctica estatal, la Corte mantendría la facultad de interpretar, extensiva o restrictivamente, los conceptos clave de la estabilidad presupuestaria constitucionalizada, pudiendo con ello disponer de un amplio margen de acción dado lo indeterminado de tales categorías (recordemos, por ejemplo, la polémica en torno a los superávits acumulados y el concepto de revenues). La Proposición Danforth, por tanto, intentaba calmar a los más

96 Donald Tobin, ibid.: 185 y 186.

97 También es relevante al efecto el alcance de la jurisprudencia establecida en Asarco $v$. Kadish, donde se permite que las Cortes estatales conozcan de la constitucionalidad (respecto de la Constitución federal) de las leyes federales que se aplican en sus Estados, aun cuando la propia Corte Suprema no pueda hacerlo. Donald Tobin, ibid.: 187.

98 Sobre el activismo judicial en Estados Unidos, es famosa ya la obra de Edouard Lambert, El gobierno de los jueces, (Madrid: Tecnos, 2010).

99 «The power of any court to order relief pursuant to any case or controversy arising under this article shall not extend to ordering any remedies other than a declaratory judgment or such remedies as are specifically authorized in implementing legislation pursuant to this section.» 
reacios a que el Poder Judicial pudiera ejecutar forzosamente el mandato constitucional, al tiempo que permitía cierto ámbito de disponibilidad por parte de la Corte para que la enmienda no se quedara, simplemente, en papel mojado. La Proposición, sin embargo, fue finalmente retirada por la confusión que añadía a la enmienda, y aunque se intentaron aprobar otras en ese sentido, como la presentada por el senador Johnston ${ }^{100}$, la enmienda, antes de ser rechazada en su totalidad, no llegó a incorporar ninguna previsión específica para frenar la posible involucración judicial.

Así pues, parece que el Congreso no quería zanjar la cuestión en sede constitucional para trasladar el debate de la ejecutabilidad a la legislación de desarrollo, a pesar de que ésta, caso de darse, se aprobaría en un contexto de indefinición absoluta del papel de la Corte Suprema en su propia interpretación, por lo que podría volver a presentar la misma ineficacia jurídica que la propia disposición constitucional que le otorga la cobertura ${ }^{101}$.

Sea como fuere, si la enmienda hubiera entrado en vigor sin tales previsiones y la cuestión se hubiera mantenida abierta, aun sin legislación de desarrollo, lo más seguro es que tarde o temprano la Corte Suprema habría tenido que intervenir para clarificar interpretativamente los conceptos esenciales de la $\mathrm{BBR}^{102}$. De hecho, el propio control jurisdiccional de constitucionalidad en Estados Unidos descansa en el cierre jurisprudencial de una cuestión que, premeditadamente o no, los Padres Fundadores dejaron abierta en el texto constitucional (Marbury v. Madison) $)^{103}$.

Cuestión distinta, sin embargo, es la de la ejecutabilidad del núcleo de la BBR a través de la intervención directa en la política presupuestaria, pues todas las dudas de naturaleza técnica, política o teórica, se cernerían de inmediato sobre tal posibilidad, y con un problema añadido pocas veces analizado: la posibilidad misma de que los destinatarios de las órdenes judiciales en materia presupuestaria no las cumplan o utilicen subterfugios para tal fin. Una orden de la Corte Suprema al Congreso para que enmiende sus propios presupuestos por considerarlos inconstitucionales puede presentar innumerables problemas en su cumplimiento y ejecución, desde los plazos para hacerlo a la renuencia misma de los representantes. La pérdida

${ }^{100}$ Creemos, además, que era aún más confuso: «No court shall have the power to order relief pursuant to any case or controversy arising under this article, except as may be specifically authorized in implementing legislation pursuant to this section.»

101 Donald Tobin, ibid:: 184.

102 Para una opinión contraria a esta suposición, puede verse David Lubecky, «The proposed Federal Budget Amendment: The Lesson From State Experience», University of Cincinnati Law Review, ${ }^{\circ}$ 55, (1986).

103 Gabriel Moreno González, «El control jurisdiccional de constitucionalidad: la experiencia estadounidense como paradigma del activismo judicial», Anuario de la Facultad de Derecho, Universidad de Extremadura, nº 29, (2011). 
de legitimidad de la Corte ante mandatos tan difíciles de cumplir si no media voluntad explícita, junto al daño producido a la Constitución como norma suprema y jurídicamente vinculante, son variables que han de tomarse en cuenta en cualquier valoración sobre el particular ${ }^{104}$. Siguiendo a Crosthwait, «frente a la repetida y flagrante desobediencia de sus órdenes por parte de las ramas electas, la Corte Suprema perdería la inefable legitimidad y respeto sobre los que su efectividad en el esquema constitucional de gobierno depende» ${ }^{105}$.

El éxito de la Constitución de los Estados Unidos, la federal más antigua en vigor, descansa en la neutralidad de los mecanismos de toma de decisión que establece en un contexto donde ningún objetivo sustancial concreto es constitucionalizado. Como compromiso entre diferentes intereses e idearios que fue, la Constitución no bendice ninguna meta específica con el poder jurídico de su virtualidad supralegal, limitándose a permitir cualquiera dentro del respeto a los derechos fundamentales por ella consagrados y del marco procedimental constituido ${ }^{106}$.

Como recuerda Kinkopf, «los Fundadores entendieron perfectamente que los intentos de definir y resolver disputas en la Constitución misma, harían de ésta un conjunto de «inútiles pergaminos» que no podrían ser ejecutados» ${ }^{107}$. Y ello ha de ser proyectado, especialmente, sobre el papel de la Corte Suprema y del Poder Judicial en la medida en que encarnan per se la neutralidad que se

${ }^{104}$ Neil Kinkopf, ibid.: 12: «Some have suggested that even if the amendment failed to eliminate the deficit, it would nonetheless have the salutary effect of creating pressure to reduce the deficit. While this might be true, the effect would come at considerable cost. Even supposing that the amendment brought about a reduction in the size of the deficit, the remaining excess of expenditures over receipts would constitute a continuing multi-billion-dollar violation of the Constitution, every day that the budget is not in balance. For how long would we as a people continue to make difficult decisions to comply with the First amendment or with the Due Process or Takings Clauses of the Fifth Amendment if we had routinely failed, for lack of an enforcement mechanism, to come within billions of dollars of complying with the most recent amendment to our Constitution?»

${ }^{105}$ Gay Crosthwait, ibid.: 12. : «Faced with repeated and flagrant disobedience of its orders by the elected branches, the Supreme Court would lose the ineffable legitimary and respect upon which its effectiveness in the constitutional scheme of government depends.» Traducción propia.

106 En este sentido, la única enmienda que incorporó al texto constitucional un objetivo concreto y sustancial ha sido también la única en ser derogada. Nos referimos a la Enmienda XVIII (1920) que estableció la conocida como «ley seca», que sería derogada por la Enmienda XXI (1933).

107 «The Framers understood fully well that attempts to define and resolve disputes in the Constitution itself would render the Constitution a charter of useless «parchment barriers» that could not be enforced.» Neil Kinkopf, ibid.: 3. Traducción propia. 
pretende, y más en una cuestión tan compleja, abierta y dada a la discrecionalidad como la que constituye la estabilidad presupuestaria elevada a los altares de la Constitución.

\section{CONSIDERACIONES FINALES}

Desde finales de 2011, y al calor de la crisis financiera que vienen arrastrando los Estados europeos, la Unión ha ido reformando y consolidando su peculiar constitución económica en la Eurozona con el objetivo, explícito, de someterla a la estabilidad presupuestaria. A partir de 2013, como corolario, entró en vigor el Tratado intergubernamental de Estabilidad, Coordinación y Gobernanza, que se erige en el cénit del nuevo entramado normativo e institucional del control presupuestario en Europa. Entre otras previsiones, el Tratado establece la obligatoriedad, por parte de los Estados firmantes, de incorporar en el seno de sus constituciones o normas de equivalente valor, las reglas de la estabilidad presupuestaria y la sostenibilidad financiera bajo determinados parámetros macroeconómicos. España, antes de verse impelida por la vinculatoriedad del Tratado, llevó a cabo la controvertida reforma constitucional del artículo 135 que $^{108}$, anticipándose a aquél, consagró ambos principios y enlazó su concreción al andamiaje de la Unión Europea y sus Tratados ${ }^{109}$.

La balanced budget rule ha aterrizado con fuerza, de este modo, en el viejo continente y en sus sistemas constitucionales, ya sea por vía de la asunción de reformas en sus normas constitucionales o de la proyección directa sobre éstas de los nuevos mecanismos europeos de gobernanza económica ${ }^{110}$, Sin embargo, el corto recorrido temporal no ha permitido el desarrollo pleno de los nuevos límites jurídicos del marco presupuestario, lo que no obsta a que la problemática inherente a ellos subyazca y pueda aparecer en toda su virtualidad al cabo de unos años. Si el debate en torno a la efectividad y el alcance jurídicos de la constitucionalización de la estabilidad presupuestaria está lejos de cerrarse en Estados Unidos, donde la experiencia al respecto es centenaria, no lo será menos en el siempre complejo y tenso contexto europeo.

${ }^{108}$ María Josefa Ridaura, «La reforma del artículo 135 de la Constitución española: ¿Pueden los mercados quebrar el consenso constitucional?», Teoría y realidad constitucional, $\mathrm{n}^{\circ} 29$, (2012).

${ }^{109}$ Cfr. El análisis temprano de Antonio Embid Irujo, La constitucionalización de la crisis económica, (Madrid: Iustel, 2012).

${ }^{110}$ Gabriel Moreno González, «El marco teórico-constitucional de los nuevos mecanismos de gobernanza económica», en Joaquín Martín Cubas (Ed)., Constitución, política y administración: España 2017, reflexiones para el debate, (Valencia: Tirant lo Blanch, 2017): 375-389. 
Tanto desde los puntos de vista político-institucional como político-económico, la juridificación de la estabilidad presupuestaria implica consecuencias claras y directas para el núcleo mismo de la democracia constitucional. Como hemos visto, el principio y su consolidación jurídica pueden encuadrarse en el tablero liberal de poderes y su limitación, al ser en este contexto una restricción normativa al margen de discrecionalidad política de los gobernantes. La tensión entre republicanos y federalistas con la que comenzaron los primeros años de andadura de los Estados Unidos, se ha transmutado hoy en una renovada dicotomía entre los que defienden la potenciación del elemento democrático frente al constitucional, y los que, por el contrario, erigen este último en el más firme baluarte contra los pretendidos excesos del poder. El nuevo liberalismo, iniciado con el parteaguas ordoliberal en el renovado interés por la configuración apriorística del Estado, se ha centrado, a través del programa de la Economía constitucional de James Buchanan, en la erección de férreas cadenas jurídicas frente a la posibilidad democrática de determinadas políticas económicas, y lo ha hecho tomando por referente a la Constitución o a normas indisponibles para las mayorías ordinarias.

La irrupción en los 70 de lo que entonces eran los inicios de la hoy hegemónica visión neoliberal, permitió que los impulsos a favor de la restricción de la esfera de lo político mediante la petrificación de lo jurídico recobraran vigor. Los intentos por llevar a la Constitución federal de EEUU la estabilidad presupuestaria se sucedieron, pero la compleja maraña de la división de poderes y de la sui generis correlación de fuerzas norteamericana, siempre lo impidieron. No obstante, tanto las experiencias estatales al respecto, que hunden sus raíces en la primera mitad del siglo XX, como las fallidas proposiciones a nivel federal y sus correlativos debates, nos brindan un escenario único en el que poder analizar ya, desde la distancia, las dificultades ínsitas en el desarrollo e implementación de un principio tan abstracto e indeterminado como polémico.

La definición misma del alcance de la estabilidad presupuestaria y su imbricación con la sostenibilidad financiera; la necesidad de articular mecanismos que flexibilicen su aplicación en determinadas situaciones; la compatibilidad entre la regla misma y los contenidos accesorios que quieran acompañarla; las posibilidades de evasión que permite su inconcreción o, por último, y quizá lo más relevante, la problemática que suscita su ejecutoriedad judicial...son las cuestiones más latentes que habrán de resolverse en la práctica conforme el nuevo marco se vaya perfeccionando (si es que logra hacerlo). Y ello si se consigue, previamente, dotar de un soporte normativo adecuado y legítimo, y de una fundamentación democrática suficiente, a un principio que está llamado a integrarse en ámbitos indisponibles alejados del cambiante vaivén de las mayorías que se alternan en el poder político. La excesiva juridificación de éste como corolario de la petrificación de determinados intereses ideológico-normativos, 
se convertirá, si es que no lo ha hecho ya, en una constante interpelación al Derecho constitucional y sus categorías más esenciales para las que los juristas debemos, previamente, armarnos con el conocimiento de las experiencias comparadas. El largo recorrido teórico, normativo y práctico de la estabilidad presupuestaria en Estados Unidos, tanto a escala estatal como federal, nos lo puede proporcionar, aunque las soluciones últimas a los problemas democráticos de fondo en la Unión Europea deberán partir de la exégesis de nuestras posibilidades, pretensiones y esperanzas ${ }^{111}$.

\section{BIBLIOGRAFIA}

Ackerman, B. We the People: Foundations, (Cambridge: Cambridge University Press, 1991): pp. 86-112.

ARENDT, H. Sobre la Revolución (Madrid: Alianza Editorial, 2013).

Berstein, R. y Agel, J. Amending America, (Kansas: University Press of Kansas, 1995).

Bayoumi, T. y Eichengreen, B. «Restraining Yourself: The Implications of Fiscal Rules for Economic Stabilization», Staff Papers, International Monetary Fund, $42, n^{\circ} 1,(1995)$.

Blanco ValdÉs, R. El valor de la Constitución (Madrid: Alianza Editorial, 1998), pp. 98 y ss.

BobBIO, N. Liberalismo y democracia (México DF: Fondo de Cultura Económica, 2000).

Bowen, J. «Enforcing the Balanced Budget Rule», Seton Hall Constitution, $\mathrm{n}^{\circ} 4$, (1993): pp. 569 y ss.

Brinton CRANE, The Anatomy of Revolution (Nueva York: Vintage Books, 1965).

Buchanan, J. Los límites de la libertad: entre la anarquía y el Leviatán, (Buenos Aires: Katz Editores, 2009).

Buchanan, J. «Clarifying confusion about the Balanced Budget Amendment», National Tax Journal, XLVIII, no 3 (1995): pp. 347 y ss.

Buchanan, J. y Wagner, R. Democracy in Deficit: The Political Legacy of Lord Keynes, (New York: Academic Press, 1977).

Buchanan, J. y BRENNAN, G. El poder fiscal: fundamentos analíticos de una constitución fiscal, (Madrid: Unión Editorial, 1987).

Buchanan, J. «Clarifying Confusion About the Balanced Budget Amendment», National Tax Journal, 48, no 3, (1995): pp. 350 y ss.

Bunch, B. «The Effect of Constitutional Debt Limits on State Governments' Use of Public Authorities», Public Choice, 68, no 1/3, (1991): pp. 57-69.

CAIN, B. y Noll, R.«Institutional causes of California's Budget Problem», Stanford Institute for Economic Policy Research, $\mathrm{n}^{\mathrm{o}}$ 10, (2010).

111 Al respecto, y con carácter valorativo, hago mía la tesis del último y brillante libro del profesor Juan Luis Requejo Pagés, El sueño constitucional, (Oviedo: KRK Ediciones, 2016). 
Caplan, R. Constitutional Brinkmanship: Amending the Constitution by National Convention, (New York: Oxford University Press, 1998): pp. 78 y ss.

Crosthwait, G. "Article III: Problems in enforcing the Balanced Budget Amendtment», Columbia Law Review, no 83, (1983): pp. 11 y ss.

Davis, L. y Cull, R. «International Capital Movements and American Economic Growth 1820-1914», en Stanley Engerman y Robert Gallman., eds., The Cambridge Economic History of the United States (Nueva York: Cambridge University Press, 1993).

Dellinger, W. «The Recurring Question of the 'Limited' Constitutional Convention», Yale Law Journal, 88, ${ }^{\circ}$ 8, (1979).

De Tocqueville, A. La democracia en América (Madrid: Editorial Aguilar, 1989).

Fioravanti, M. Los derechos fundamentales (Madrid: Trotta, 2003).

ELLIS, J. Founding Brothers (Nueva York: Vintage Books, 2000).

ELSTER, J. Ulises y las sirenas: estudios sobre la racionalidad e irracionalidad, (Madrid: Fondo de Cultura Económica de España, 2002).

EMBID IRUjo, A. La constitucionalización de la crisis económica, (Madrid: Iustel, 2012).

FelD, L. y KIRCHGÄSSNER, G. «On the Effectiveness of Debt Brakes: The Swis Experience», Center for Research in Economics, Management and the Arts, Working Paper, $n^{\circ} 21$, (2006): pp. 3 y ss.

JEFFERSON, T. «Letter to John Taylor of Caroline», November 26, 1798, en The Writings of Thomas Jefferson (Washington DC: Memorial Edition), vol. 10.

Heun, W. «Balanced Budget Requirements and Debt: Brakes feasibility and Enforcement», German Economic Review, 15, n 1, (2014): pp. 105 y ss.

Hou, Y. y SMITH, D. «Framework for Understanding State Balanced Budget Requirement Systems: Reexamining Distintive Features and an Operational Definition», Public Budgeting and Finance Review, 26, n 3, (2006): pp. 32-43.

KEECH, W. «A Theoretical Analysis of the Case for a Balanced Budget Amendment», Policy Sciences, 18, n 2, (1985).

KIEwiet, R. y Szakaly, K. «Constitutional Limitations on Borrowing: An Analysus if State Bonded Indebtedness», California Institute of Technology (1996): pp. 65 y ss.

KINKOPF, N. «The Balanced Budget Amendment: A Threat to the Constitutional Order», Georgia State University Publications, 11, no 1, (2011): pp. 6 y ss.

KIRKLAND, K. «Creative accounting and short-term debt: State responses to the deficit threat», National Tax Journal, 36., n 3, (1983).

KRISHNAKUMAR, A. «In defense of the debt limit statute», Harvard Journal on Legislation, 42, no 71 (2005): pp. 140-145.

KYviG, D. «Refining or Resisting Modern Government? The Balanced Budget Amendment to the U. S. Constitution», Akron Law Review, 28, no 2, (1995): pp. 103 y ss.

KutTNER, R. Revolt of the Haves: Tax Rebellions and Hard Times, (Nueva York: Simon and Schster, 1980).

LAMBERT, E. El gobierno de los jueces, (Madrid: Tecnos, 2010).

LuBECKY, D. «The proposed Federal Budget Amendment: The Lesson From State Experience», University of Cincinnati Law Review, ${ }^{\circ}$ 55, (1986). 
Manasse, P. «Deficit Limits, Budgets Rules and Fiscal Policy», IMF Working Paper, (2005).

Moreno GonzÁlez, G. «El marco teórico-constitucional de los nuevos mecanismos de gobernanza económica», en Joaquín Martín Cubas (Ed)., Constitución, politica y administración: España 2017, reflexiones para el debate, (Valencia: Tirant lo Blanch, 2017): pp. 375-389.

Moreno GonZÁlez, G. «El control jurisdiccional de constitucionalidad: la experiencia estadounidense como paradigma del activismo judicial», Anuario de la Facultad de Derecho, Universidad de Extremadura, no 29, (2011).

Morgan, I. «Unconventional Politics: The Campaign for a Balanced Budget Amendment. Constitutional Convention in the 1970s», Journal of American Studies, Cambridge University Press, $n^{\circ} 32$, (1988): pp. 422 y ss.

Morris, R. «Evading Debt Limitations with Public Building Authorities: The Costly Subversion of State Constitutions», The Yale Law Journal, 68, $\mathrm{n}^{\circ} 2$, (1958).

Needelman, J. «Deconstructing the Balanced Budget Amendtment: Fiscal Folly, Monetary Madness», UCLA Law Review, n 44 (1997): 1289 y ss.

O’Sullivan, A., Sexton, T. y Sheffrin, S. «Proposition 13: Unintended Effects and Feasible Reforms», National Tax Journal, n 55, (1999).

Poterba, J. «Do Budget Rules work?», National Bureau of Economic Research, working paper 5550, (1996): pp. 15-25.

PoterbA, J. «Balanced Budget Rules and Fiscal Policy: Evidence From the States», National Tax Journal, 48, (1995).

PuY Fraga, P. Economía política del Estado constitucional: fundamentos de la Economía constitucional, (Barcelona: Cedecs Editorial, 1996).

REQuejo PAgés, J.L. El sueño constitucional, (Oviedo: KRK Ediciones, 2016).

SAturno, J. y LYNCH, M. «A Balanced Budget Constitutional Amendment: Background and Congressional Options», Congressional Research Service, $\mathrm{n}^{\circ} 20$ (2011): p. 2 y ss.

Savage, J. Balanced Budgets and American Politics, (New York: Cornell University Press, 1988).

SETo, T. «Drafting a Federal Balanced Budget Amendment That Does What It Is Supposed To Do (And No more)», The Yale Law Journal, 106, $\mathrm{n}^{\circ}$ 5, (1997): pp. 1467 y ss.

Stokes Paulsen, M. «A General Theory of Article V: The Constitutional Lessons of the Twenty-seventh Amendment», Yale Law Journal, 103, no 8, (1993).

ReQueJo PAgÉs, J.L. El sueño constitucional, (Oviedo: KRK Ediciones, 2016).

RIDAURA, M J.«La reforma del artículo 135 de la Constitución española: ¿Pueden los mercados quebrar el consenso constitucional?», Teoría y realidad constitucional, $n^{\circ} 29,(2012)$.

Stokes Paulsen, M. «A General Theory of Article V: The Constitutional Lessons of the Twenty-seventh Amendment», Yale Law Journal, 103, $\mathrm{n}^{\circ}$ 8, (1993).

SuITs, D. y Fisher, R. «A Balanced Budget Constitutional Amendment: Economic Complexities and Uncertainties», National Tax Journal, 38, nº 4, (1985).

Sung Hanm, Mark, Kamlet, David Moewry y Tsai Tsu Su, «The influence of the Gramm-Rudman-Hollings Act on Federal Budgetary», Journal of Policy Analisys and Manageme, 11, $\mathrm{n}^{\mathrm{o}}$ 2, (1992). 
TRIBE, L. «Issues Raised by Requesting Congress to Call a Constittutional Convention to Propose a Balanced Budget Amendment», Pacific Law Journal, 10, (1979).

Vallespín, F. Nuevas teorías del contrato social: John Rawls, Robert Nozick y James Buchanan, (Madrid: Alianza Editorial, 1985).

WILDAVsKy, A. «A Cultural Theory of Expenditure Growth and (Un)balanced Budgets», Journal of Public Economics, 28, no 3 (1985): pp. 349-357. 